\title{
Article
}

\section{Moving surface boundary layer control analysis and the influence of the Magnus effect on an aerofoil with a leading-edge rotating cylinder}

\author{
Md. Abdus Salam ${ }^{1, *}$, Bhuiyan Shameem Mahmood Ebna Hai ${ }^{2, \dagger}$, M. A. Taher Ali ${ }^{1}$, Debanan \\ Bhadra $^{1}$, and Nafiz Ahmed Khan ${ }^{1}$ \\ 1 Department of Aeronautical Engineering, Military Institute of Science and Technology, Dhaka, Bangladesh. \\ 2 Faculty of Mechanical Engineering, Helmut Schmidt University, Hamburg, Germany. \\ * Lead author; E-mail: head@ae.mist.ac.bd. \\ † Corresponding author; E-mail: shameem.ebna.hai@hsu-hh.de.
}

\begin{abstract}
A number of experimental and numerical studies point out that incorporating a rotating cylinder can superiorly enhance the aerofoil performance, especially for higher velocity ratios. Yet, there have been less or no studies exploring the effects of lower velocity ratio at a higher Reynolds number. In the present study, we investigated the effects of Moving Surface Boundary-layer Control (MSBC) at lower velocity ratios (i.e. cylinder tangential velocity to free stream velocity) and higher Reynolds number on a symmetric aerofoil (e.g. NACA 0021) and an asymmetric aerofoil (e.g. NACA 23018). In particular, the aerodynamic performance with and without rotating cylinder at the leading edge of the NACA 0021 and NACA 23018 aerofoil was studied on the wind tunnel installed at Aerodynamics Laboratory. The aerofoil section was tested in the low subsonic wind tunnel, and the lift coefficient $\left(C_{L}\right)$ and the drag coefficient $\left(C_{D}\right)$ were studied for different angles of attack $(\alpha)$. The experiments were conducted for two Reynolds numbers $\left(R_{e}\right): 2 \times 10^{5}$ and $2.5 \times 10^{5}$ corresponding to two free stream velocities: $20 \mathrm{~ms}^{-1}$ and $25 \mathrm{~ms}^{-1}$, respectively, for six different angle of attacks (AOA) $\left(-5^{\circ}, 0^{\circ}, 5^{\circ}, 10^{\circ}, 15^{\circ}\right.$ and $\left.20^{\circ}\right)$. This study demonstrates that the incorporation of a leading edge rotating cylinder results in an increase of lift coefficient at lower angle of attacks (maximum around $33 \%$ ) and delay in stall angle (from $10^{\circ}$ to $15^{\circ}$ ) relative to the aerofoil without rotating cylinder.
\end{abstract}

Keywords: Moving surface boundary layer control; symmetric aerofoil; velocity ratio; Magnus effect; lift coefficient; drag coefficient

\section{Introduction}

The aerodynamic efficiency of an aerofoil can be enhanced by incorporating a rotating cylinder at the leading edge of an aerofoil, nullifying the adverse effects of a boundary layer. Momentum injection by the rotating body helps to delay the flow separation, which acts in an advantageous way for the aerofoils. The injection of momentum enhances the aerodynamic performance of aerofoil by keeping the flow attached over the top surface of aerofoil at a higher angle of an attack. The additional momentum charges the boundary layer, which results in an increased suction on a top surface. With an increase in rotational speed and the velocity ratio, the lift coefficient increases significantly, albeit at a cost of an increment in drag. The stall angle also delays due to the incorporation of the rotating cylinder. After all, the improved aerodynamic efficiency of aerofoils will increase the performance of a wing, horizontal tail and vertical tail automatically, because all these are formed by placing the aerofoil sections in various spans-wise combinations.

There is an increasing body of literature, including both experimental and numerical studies, exploring the potential for an advance in the performance of aerofoils and aircrafts. The approaches to augmenting the aerofoils efficiency include boundary layer suction, boundary layer blowing, vortex generator, boundary layer control etc. [1]. Meanwhile, less efforts has been made in investigating the influence of the Magnus Effect on the aerofoil characteristics. In 1852, the German scientist, Gustav 
Magnus, noticed that lift force is also generated by spinning balls [2]. This effect is called Magnus Effect, and a lift force caused by a spin is called a Magnus force. Owing to its potential gain, scientists have tried to employ this effect, albeit in different fields. The use of the effect by incorporating a rotating cylinder at the leading edge of the aerofoils to amplify its performance has received less attention. For the last 35 years, the state of research has not experienced large changes. Meanwhile, this concept has two advantages: lift production because of Magnus Effect and Boundary Layer Control.

Modi and his team were prominent researchers in this field, who carried out several experimental and numerical studies to appreciate the effect of moving surfaces on the aerofoils boundary layer control and the increment of aerofoils performance [3-10]. They conducted experiments with many alternative configurations of the position of the rotating cylinder. They have documented the potential results in the increment of the lift to exceed $100 \%$ and the stall angle to reach more than $30^{\circ}$ in high velocity ratios. Mokhtarian et al. conducted similar investigation, analysing the effects of MSBC using a leading-edge rotating cylinder in symmetrical Joukowski aerofoil numerically and asymmetric NACA 63218 aerofoil experimentally [11]. They have documented an increment in lift and stall angle for both cases for high velocity ratios.

Johnson et al. conducted an experiment with a leading edge rotating cylinder and a flap. He was interested in the effect of MSBC at a velocity ratio up to 1.2 [12]. Tennant et al. conducted a research incorporating a trailing edge rotating cylinder and documented potential outcome of $C_{L}=1.2$ for higher velocity ratio [13]. They also explored the growth of the boundary layer on the moving surface $[14,15]$. Mokhtarian studied the effect of MSBC incorporating a scooped leading edge rotating cylinder and concluded that although it would outperform solid leading edge rotating cylinder at low velocity ratios [16]. But at high velocity ratios, the scooped cylinder acted as a solid rotating cylinder and no specific superiority was documented. Hassan et al. studied the effects of MSBC on a symmetric NACA 0012 and asymmetric NACA 63218 aerofoil [17]. He documented that for a subcritical flow the effect would be beneficial in contrast to the supercritical flow where the drag increased severely.

In 2000, an experimental study was conducted on NACA 0024 with a leading edge rotating cylinder and a flap [18]. They found that the drag increases with velocity ratio. Simulation of NACA 63218 aerofoil with leading edge rotating cylinder was conducted in 2015 [19]. Yet, this study was also limited to the effects at higher velocity ratios. The comprehensive literature review on Magnus effect was conducted in 2015, providing a very useful reference for the researchers in this field [20]. Moreover, the application of this Magnus Effect on aircraft wing was studied by Patkunam [21]. Patkunam et al. proposed the so-called Flo-Lapse approach, showing how incorporating Magnus Effect effects the wing of an aircraft, increasing the aircraft performance. Yet, this study was restricted to angle of an attack ranging from $0^{\circ}$ to $5^{\circ}$. Besides, in 2016, Kenyon [22] published his research in the natural science field, where he developed two algebraic formulas for calculation of Magnus Force. Again, in the field of applied mechanics, Sailaranta [23] studied the influence of the Magnus Effect on the flight of a fast spinning vehicle at high angle of attack. He also investigated the possibilities to limit the terminal velocity and a range of a bullet with the aid of the Magnus Effect.

In 2007, Chen Li, carried out an experimental analysis as part of his Masters thesis with a leading edge rotating cylinder on a NACA 0015 aerofoil [24]. The free stream velocity was kept constant at 15 $\mathrm{ms}^{-1}$ and the coefficient of lift and coefficient of drag were measured at velocity ratios 0.5, 1.0 and 1.4. The chord length in the study was $400 \mathrm{~mm}$. The Reynolds number was around 400, 000 high due to its large chord length.

In 2009, Buerge [25] carried out an experiment with a rotating cylinder installed below and close to the trailing edge of a Clark $\mathrm{Y}$ aerofoil. The purpose of this vortex flap was not to control the boundary layer, but rather it was envisioned to be incorporated as an element of a high lift device. In their investigation, the gain in $C_{L_{\max }}$ was much larger relative to the base aerofoil and it was around $200 \%$.

In 2010, Zhang et al. computationally validated the experimental analysis of Chen $\mathrm{Li}$ [26]. For this, they used the SST-two equation model. The $C_{L_{\max }}$ was around 0.9 and 1.2 at velocity ratio 0.5 and 1.0, respectively. They also developed an optimized design for the total of 25 aerofoils, where the 
$C_{L_{\max }}$ was documented at 2.7 for a velocity ratio of 1.4. In 2011, Sahu et al. conducted a computational analysis on NACA 0012 aerofoil incorporating momentum injection with a rotary actuator disk at $\mathrm{R}_{e}$ No. 46, 400 [27]. They documented an increase in lift and a decrease in a drag with the modified aerofoil relative to the base aerofoil. However, the Reynolds number in their study was much lower.

In 2014, Ahmed et al. conducted a computational analysis on the effects of MSBC on NACA 0024 aerofoil [28]. They documented an increment in lift co-efficient of $36 \%$ relative to the base aerofoil and increment in stall angle of $122 \%$ relative to the base aerofoil. Welsh et al. conducted an investigation on the effects of MSBC on NACA 0015 aerofoil and concluded that the stall angle had increased by $11^{\circ}$ in the modified aerofoil relative to the base aerofoil [29]. They didn't mention changes to the drag.

In 2015, Huda et al. conducted a computational analysis of the effect of MSBC on NACA 0010 aerofoil [30]. They documented an increment of lift by $145 \%$ relative to the base aerofoil at velocity ratio 2.0. But their research was restricted to only two velocity ratios: 0 and 2 respectively. In 2017, Faisal et al. conducted an investigation on controlling the flow using a rotating cylinder at the leading edge of NACA 0018 aerofoil [31]. Their study was limited to only symmetric aerofoil. Effect on the asymmetric aerofoil was absent from their investigation. Alias et al. carried out computational analysis of the effect of rotating cylinder on concentrated flow. Their study showed a potential increment in lift coefficient. Yet, they didn't consider aerofoil [32]. In 2018, Abdulla et al. conducted a computational analysis on the effect of the gap between leading edge cylinder and aerofoil [33]. They concluded that the maximum value of a lift to drag ratio was obtained at each and every velocity ratios in their investigation (1,2 and 3$)$ when the gap was kept at $3 \mathrm{~mm}$. Yet, they analysed the effects at high velocity ratios only. Vinayak et al. investigated the Magnus effect and circulation theory on NACA 2412 aerofoil and documented a potential increment in lift and stall angle [34]. Their study also indicated high drag in the modified aerofoil relative to the base aerofoil. The growing number of studies indicate the interest and active research into the implications of Magnus effect.

The present study explores the effects of MSBC in lower velocity ratios in a symmetric NACA 0021 aerofoil. To this end, the existing literature is limited to insignificant Reynolds number effects because of low free stream velocity. We also focus on the effects of MSBC at higher Reynolds number. In addition, we carry out a comparative analysis of the power requirement for rotating the cylinder with respect to the enhancement of lift. We found that the power requirement was negligible compared to the enhancement of lift. One example of the use of the concept is its implemented in a short takeoff and landing (STOL) aircrafts, as they require high lift coefficient at low angle of attacks. In addition, the current study shows the practicability of incorporating leading edge rotating cylinder for a thick aerofoil in aviation. Besides, for some applications in wind turbine blades and control surfaces of aircraft this research indicates the superiority of lift at a low power requirement. In case of achieving the optimum design of aerofoil for effective performance, this concept can be implemented on a large scale.

\section{Theoretical background}

Modi et al. analyzed the effects of MSBC with a 16\% thick, symmetric Joukowski aerofoil at high Reynolds number [10]. The aerofoil stalled at an angle of attack of $12^{\circ}$. However, they provided a leading edge rotating cylinder to control the flow around an aerofoil to enhance the lift. The control of the boundary layer via rotation or movement of a surface can be expressed by the term Moving Surface Boundary-layer Control or MSBC. It is likely that at some point of the fluid flow (after $12^{\circ}$ angle of attack), the boundary layer of the fluid was separated from the aerofoil body. This separation occurred when the flow pressure was increased in the flow direction, the phenomenon known as the adverse pressure gradient. 


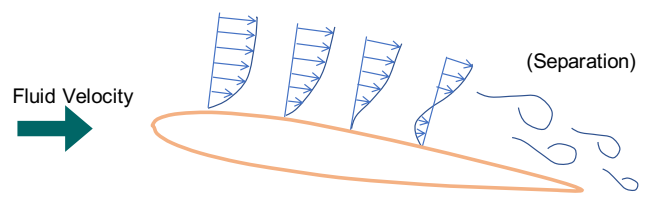

(a)

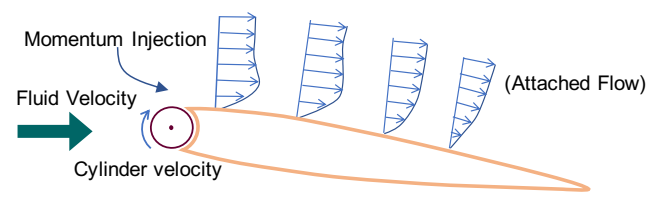

(b)

Figure 1. (a) Illustration of the concept of flow separation: the flow is separated at some distance from the leading edge of the aerofoil. (b) Illustration of the concept of Momentum Injection: the fluid is attached to the aerofoil.

The increment of the fluid pressure is comparable to the increment of the potential energy of the flow. As the potential energy is increased, the kinetic energy as well as the fluid velocity is decreased. Consequently, the gradient of the velocity profile is decreased along with the decrease in a wall shear stress. As the adverse pressure gradient increase substantially, the wall shear stress is reduced to zero, which results in flow separation. Figure-1a offers a graphical representation of this concept.

With the help of the momentum injection via rotating cylinder they documented an increase in stall angle near 360 and lift coefficient of around 1.5. Figure- $1 \mathrm{~b}$ illustrates the effect of rotation of moving surface. When more energy is injected into the flow, the gradient of the velocity profile is increased. Therefore, the flow remains attached to the aerofoil body. This resulted in increment of stall angle and lift coefficient. However, for stationary cylinder, the coefficient of lift was less than the base aerofoil.

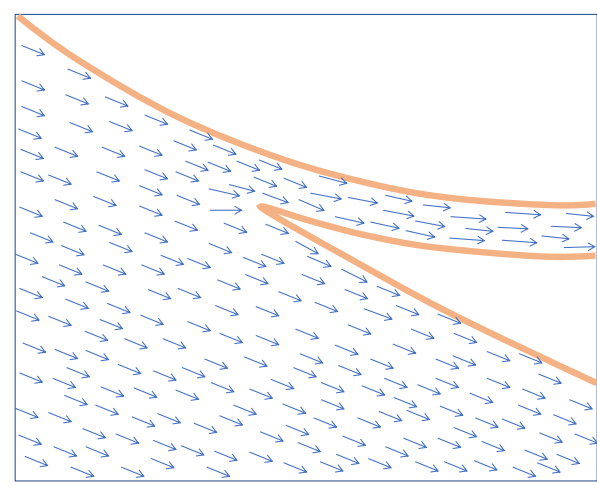

(a)

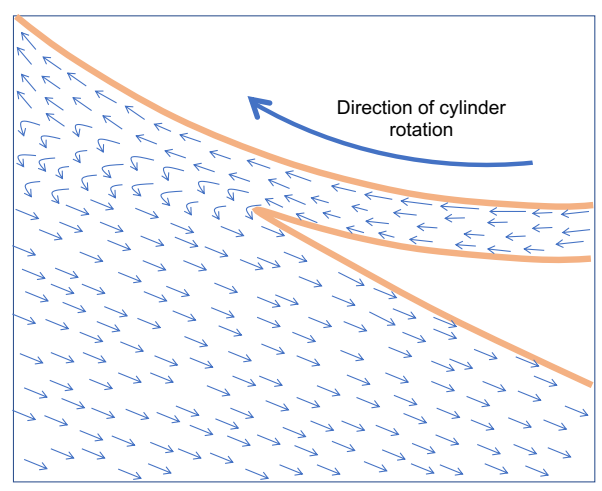

(b)

Figure 2. (a) Illustration of the air flow direction for stationary cylinder, (b) Illustration of the air flow direction for rotating cylinder.

Figure-2 illustrates the air flow direction in case of a stationary cylinder (left) and rotating cylinder (right). In case of stationary cylinder, the air flow enters from the lower part of the gap between the cylinder and aerofoil and leaves from the upper part of the gap. Therefore, no enhancement of lift was detected in this case.

They also documented the effect of MSBC in drag coefficient. The drag coefficient increased more than in the case of stationary cylinder and up to the angle of attack of 200. For the rotating cylinder, the air flow leaves from the lower part of the gap and mixes with the free air stream. Further, the inflow air gets shoved away near the lower part of the gap from the bottom part of the aerofoil. Therefore, it creates a recirculation zone at the opening of the bottom part of the aerofoil. It is one of the contributing factors in creating more drag than in the case of stationary cylinder. However, stronger increase in the rotation leads to the reduction of the drag.

This research work showed the comparison of lift coefficient between the base aerofoil and modified aerofoil. Yet, the comparison of drag coefficient between the base aerofoil and modified aerofoil was absent. Furthermore, the study lacks the case of the effects of MSBC in low velocity ratios. In the current study, the characteristics of lift co-efficient, drag co-efficient and stall angle were analysed 
and compared between the base and modified aerofoil. The studies mentioned in the previous section haven't considered the MSBC at low velocity ratios.

\section{Experimental investigation}

Modi et al. carried out numerous experiments on the effects of MSBC for aerofoils and different bluff bodies like prisms, flat plates, square plates, tractor trailer configurations, etc. They conducted an experiment on a symmetric $15 \%$ thick Joukowski aerofoil at a low Reynolds number. The result showed a potential increase of $C_{L}\left(C_{L_{\max }}=2\right.$ at $\left.\frac{U_{c}}{U}=4\right)$ as the velocity ratio increases. But at $\frac{U_{c}}{U}=1$, $C_{L_{\max }}$ was around 1.1 and stall angle was 160 . Analysis of the behaviour of the flow for velocity ratios lower than that was missing in their study [3]. Garni et al. experimented with a symmetric NACA 0024 aerofoil with and without the deflection of flap [18]. In their study at $\frac{U_{c}}{U}=1$, the maximum lift coefficient was documented around 1.2 and the stall angle was $20^{\circ}$. The drag co-efficient for the case of $\frac{U_{c}}{U}=1$ was increasing gradually with the increment of angle of attack and reached a maximum value at around 1.0 at 400 angle of an attack. The study didn't mention any effects at lower velocity ratios and was conducted on a lower Reynolds number compared to the current study.

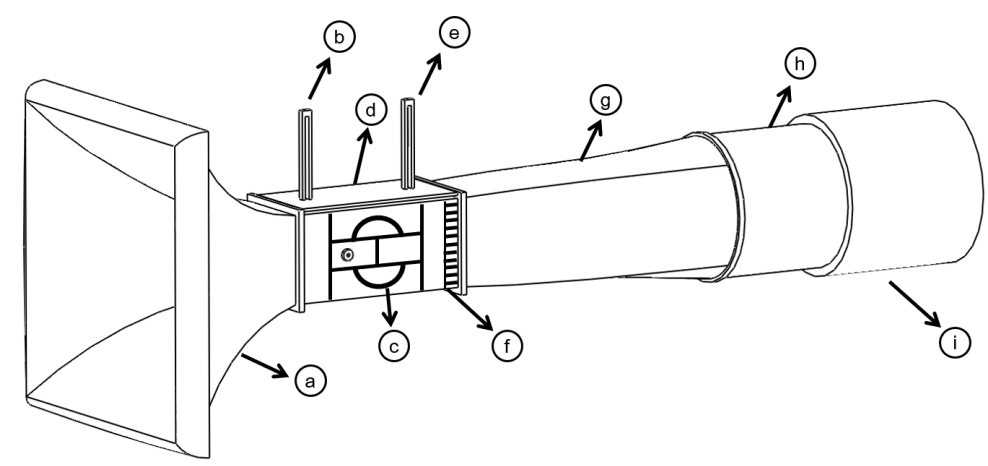

Figure 3. Schematic diagram of the wind tunnel with the components: (a) inlet cone, (b) pitot static tube, (c) angle measurement section, (d) test section, (e) traversing pitot tube, (f) safety nets, (g) diffuser, (h) axial fan unit, (i) silencer [35].

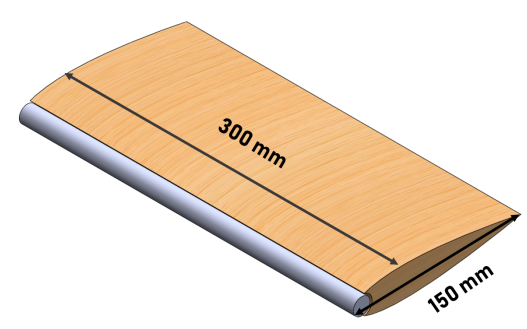

(a)

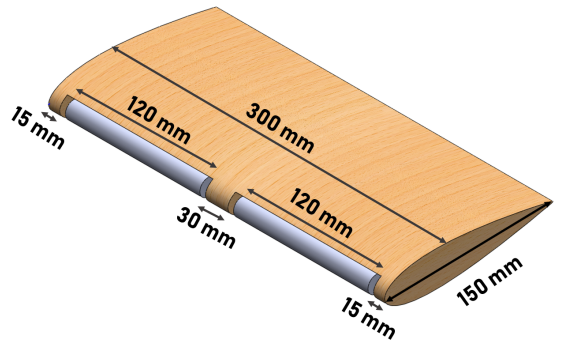

(b)

Figure 4. The geometry of the NACA 0021 aerofoil with rotating cylinder (all units are in millimetre). (a) NACA 0021 model with a groove and cylinder with coupler attached. (b) CAD model of the modified aerofoil with $60 \mathrm{~mm}$ support.

The subsonic wind tunnel (AF -100) of the Aerodynamics laboratory of the Department of Aeronautical Engineering of Military Institute of Science and Technology was utilized to conduct the experiment. For the present investigation, an open circuit subsonic wind tunnel with a working section of $300 \mathrm{~mm} \times 300 \mathrm{~mm} \times 600 \mathrm{~mm}$ was used as shown in Figures 3-4. It is a compact, open-circuit, suction wind tunnel that is useful for studying aerodynamics. The wind tunnel can be operated at a maximum free stream velocity of $50 \mathrm{~ms}^{-1}$ and the there is a capability of setting the angle of attack to up to $90^{\circ}$. The chord length of the aerofoil section was $150 \mathrm{~mm}$ and the span was $300 \mathrm{~mm}$. The 
diameter of the rotating cylinder was $15 \mathrm{~mm}$. The cylinder was rotated in $0,3000,3500,4000,4500$, and $5000 \mathrm{rpm}$. A wind tunnel model of NACA 0021 aerofoil with a chord length of $0.15 \mathrm{~m}$ with a grooved leading edge was used to accommodate the rotating cylinder. A three-component balance was installed in the test section of the wind tunnel in order to measure the pitching moment, lift, and drag. A steel rod of $10 \mathrm{~mm}$ was inserted into the three-component balance, which was in contact with the support plate. In $37.5 \mathrm{~mm}$ position from the leading edge of the aerofoil, the rod was attached to the aerofoil. The balance has the provision to place the aerofoil at a different angle of attack. The sidewall of a test section of wind tunnel was not readily prepared for carrying out the experiment. Some modifications were required to hold the motor and cylinder. Therefore, a new set of side walls was prepared. The purpose of the new set of sidewalls for the test section was to make a provision for holding the motor and the cylinder. For this experiment, it was required to change the angle of attack of the aerofoils and the position of the cylinder as well. As the cylinder was being propelled by a motor, which was located outside of the test section, a groove has to be cut at the test section on both walls. The drawings of the test section side walls were transferred to solid works software and then processed by the computer numerical control (CNC) machine. Thereby, the exact replica of the existing wind tunnel test section that fits in the wind tunnel was created.

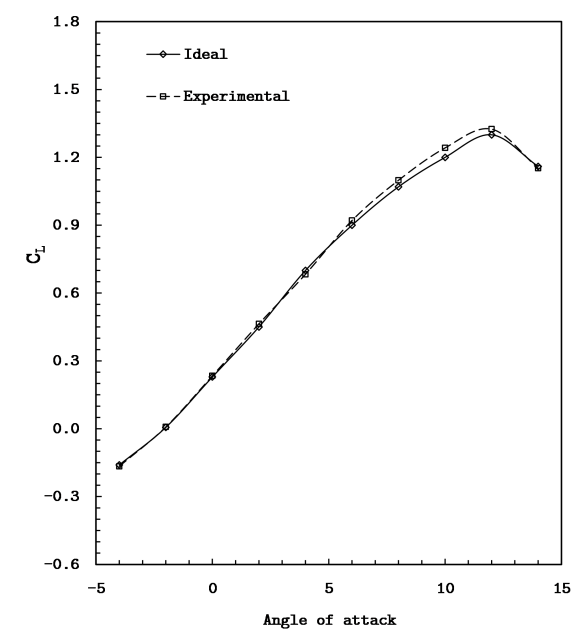

(a)

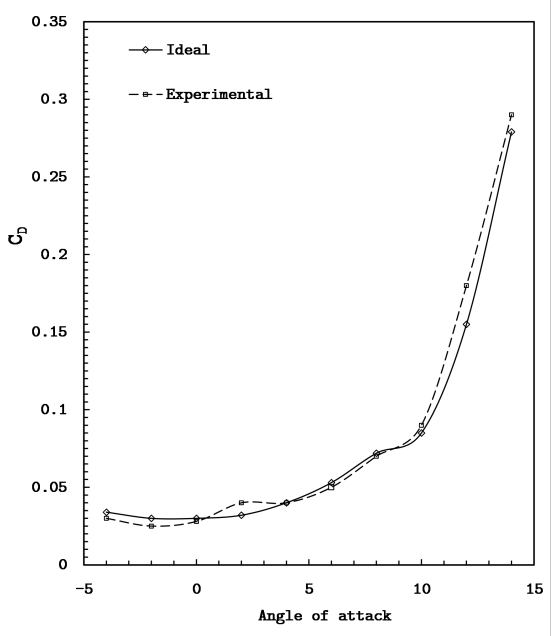

(b)

Figure 5. Experimental vs ideal values of (a) $C_{L}$, (b) $C_{D}$.

The performance of the wind tunnel was tested several times with the aerofoil supplied by the manufacturer before the measurements. AT the initial stage, the calibration of the three-component balance was done. The Three-Component Balance fits into the working section of Subsonic Wind Tunnel and offers an easy-to-use support system for wind tunnel models; it is used to measure lift, drag and pitching moment exerted on the model. To validate the calibration activities, factory provided the NACA 2412 data, which was employed for the comparison. These are presented in Figure-5.

\section{Numerical approximation}

As the flow attachment near the boundary surfaces is the main concern of this paper, that corresponding wall treatment will resolve the boundary conditions clearly. The computational domain and boundary conditions are one of the dominant factors in a computational study. The considered boundary conditions are chosen to correlate with the experimental analysis. The boundary conditions are specified in Figure-6, and in Table-1. 


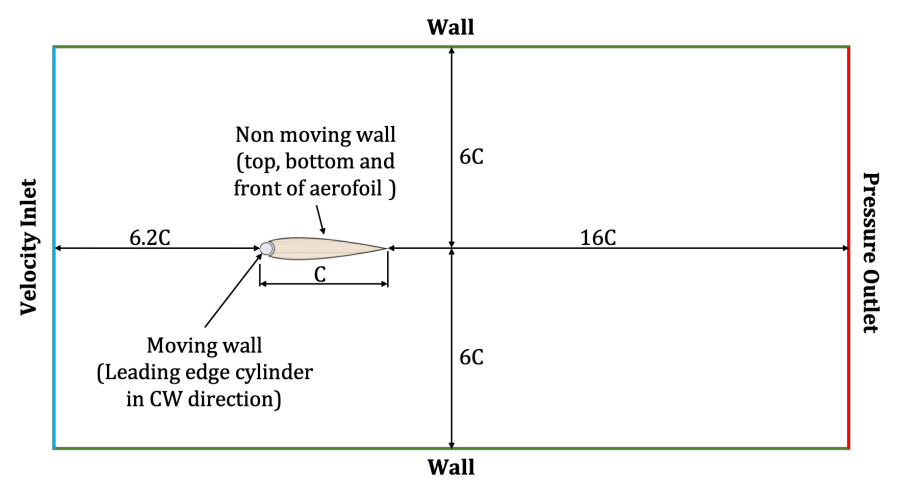

Figure 6. The configuration for the numerical test, conducted for two alternative free stream velocities: $20 \mathrm{~ms}^{-1}$ and $25 \mathrm{~ms}^{-1}$, respectively, for six different AOA $\left(-5^{\circ}, 0^{\circ}, 5^{\circ}, 10^{\circ}, 15^{\circ}\right.$ and $\left.20^{\circ}\right)$. The cylinder was rotated in 0, 3000, 3500, 4000, 4500 and $5000 \mathrm{rpm}$.

Table 1. Boundary Conditions.

\begin{tabular}{l|l}
\hline Boundary & Conditions \\
\hline Inlet & Velocity inlet $\left(v_{f}=20 \mathrm{~ms}^{-1}\right.$, and $\left.25 \mathrm{~ms}^{-1}\right)$ \\
Outlet & Pressure Outlet (do-nothing condition) \\
Wall & No-slip condition \\
Cylinder & Moving Wall (Wall motion: Rotational- uniform, \\
& $0,3000,3500,4000,4500$, and $5000 \mathrm{rpm})$ \\
\hline
\end{tabular}

The standard $k-\epsilon$ turbulence model with standard wall functions has been previously used in the numerical simulation studies [32]. The current study employs the RNG $k$ - $\epsilon$ turbulence model. Accordingly, the near wall conditions are projected using the enhanced wall treatment with the RNG $k-\epsilon$ turbulence model. The RNG $k-\epsilon$ model extends the standard $k-\epsilon$ model by adding the term $R_{\epsilon}$, arriving at [36,37]:

$$
\begin{aligned}
& \partial_{t} \rho_{f} k+\partial_{x_{i}} \rho_{f} k u_{i}=\partial_{x_{j}}\left(\alpha_{k} \mu_{e f f} \partial_{x_{j}} k\right)+G_{k}+G_{b}-\rho_{f} \epsilon-Y_{M}+S_{k}, \\
& \partial_{t} \rho_{f} \epsilon+\partial_{x_{i}} \rho_{f} \epsilon u_{i}=\partial_{x_{j}}\left(\alpha_{\epsilon} \mu_{e f f} \partial_{x_{j}} \epsilon\right)+C_{\epsilon_{1}} \frac{\epsilon}{k}\left(G_{k}+C_{\epsilon_{3}} G_{b}\right)-C_{\epsilon_{2}} \rho_{f} \frac{\epsilon^{2}}{k}-R_{\epsilon}+S_{\epsilon},
\end{aligned}
$$

where the term in the $\epsilon$ is given by

$$
R_{\epsilon}=\frac{C_{\mu} \rho \eta^{3}\left(1-\eta / \eta_{0}\right)}{1+\beta \eta^{3}} \frac{\epsilon^{2}}{k}
$$

Here, $\eta \equiv S k / \epsilon, \eta_{0}=4.38$, and $\beta=0.012$. For the high-Reynolds-number limit, $\mu_{t}=\rho C_{\mu} \frac{k^{2}}{\epsilon}$ with $C_{\mu}=0.0845$ is derived from the RNG theory. Worth noting, this value $C_{\mu}$ is rather close to the empirically-determined value of 0.09 using the standard $k-\epsilon$ model. Generally, turbulence is defined by rotation or swirl in the mean flow. In equation (1), $G_{k}=-\rho_{f} \overline{u_{i}^{\prime} u_{j}^{\prime}} \partial_{x_{j}} u_{j}$ denotes the generation of turbulence kinetic energy driven by the mean velocity gradients. $G_{b}=\beta g_{i}\left(\mu_{t} / \operatorname{Pr}_{\mathrm{t}}\right) \partial_{x_{i}} T$ denotes the generation of turbulence kinetic energy driven by buoyancy. $\mathrm{Pr}_{t}$ is the turbulent Prandtl number for energy, $g_{i}$ is the component of the gravitational vector in the $i$-th direction. For the RNG $k-\epsilon$ model, $\operatorname{Pr}_{\mathrm{t}}=1 / \alpha$. In turn, the inverse effective Prandtl numbers $\alpha_{k}$ and $\alpha_{\epsilon}$, are computed as following:

$$
\left|\frac{\alpha-1.3929}{\alpha_{0}-1.3929}\right|^{0.6321}\left|\frac{\alpha+2.3929}{\alpha_{0}+2.3929}\right|^{0.3679}=\frac{\mu_{\mathrm{mol}}}{\mu_{\mathrm{eff}}}
$$

where $\alpha_{0}=1.0$. For the high-Reynolds-number limit $\left(\mu_{\mathrm{mol}} / \mu_{\mathrm{eff}} \ll 1\right), \alpha_{k}=\alpha_{\epsilon} \approx 1.393$. The coefficient of thermal expansion is given by $\beta=-1 / \rho_{f}\left(\partial_{T} \rho_{f}\right)_{P}$. Introducing the effect of buoyancy on $\epsilon$ (in the 
Viscous Model dialog box), the value of $G_{b}$ can be found from the equation for $\epsilon$ in (1). In addition, the value $Y_{M}=2 \rho_{f} \in M_{t}^{2}$ reflects the contribution of the fluctuating dilatation in compressible turbulence to the overall dissipation rate. Here, $\mathrm{M}_{t}=\sqrt{k / a^{2}}$ denotes the turbulent Mach number, and $a \equiv \sqrt{\gamma R T}$ is the speed of sound. The quantities $\alpha_{k}$ and $\alpha_{\epsilon}$ are the inverse effective Prandtl numbers for $k$ and $\epsilon$, respectively. $C_{\epsilon_{1}}, C_{\epsilon_{2}}$, and $C_{\epsilon_{3}}$ are constants. The latter defines the degree to which $\epsilon$ is affected by the buoyancy. In ANSYS FLUENT, $C_{\epsilon_{3}}$ is not specified. Instead, it is estimated from the following equation: $C_{\epsilon_{3}}=\tanh |v / u|$ [38]. Here, $v$ denotes the component of the flow velocity parallel to the gravitational vector and $u$ is the component of the flow velocity perpendicular to the gravitational vector. In this way, $C_{\epsilon_{3}}$ will become 1 for buoyant shear layers for which the main flow direction is aligned with the direction of gravity. In case buoyant shear layers are perpendicular to the gravitational vector, $C_{\epsilon_{3}}$ will be zero; the constants $C_{\epsilon_{1}}$ and $C_{\epsilon_{2}}$ are computed using the RNG theory as mentioned earlier. In ANSYS FLUENT, the default values for $C_{\epsilon_{1}}$ and $C_{\epsilon_{2}}$ are set to 1.42 and 1.68, respectively. Values $S_{k}$ and $S_{\epsilon}$ are specified by the user. Worth noting, ANSYS FLUENT $[37,39]$ uses finite volume method for the solution of the problem.

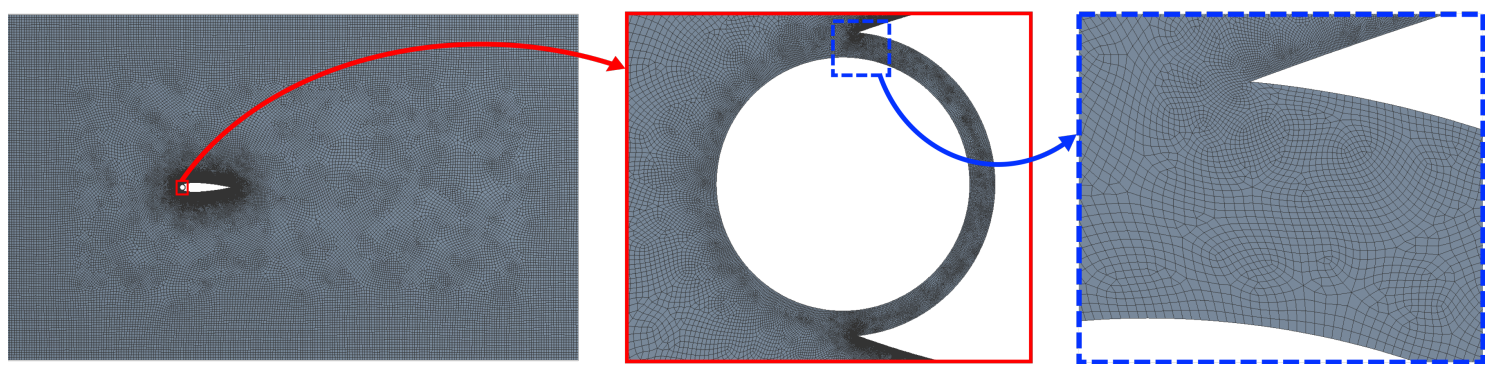

Figure 7. Unstructured mesh (quadrilaterals) in the XY plane.

Figure-7 illustrates the unstructured mesh in the $X Y$ plane at 3 alternative zoom levels. There are 500000 cells, where the mean cell size lies between $2 \times 10^{-4} \mathrm{~m}$ and $5 \times 10^{-2} \mathrm{~m}$. Figure- 8 shows the grid validation test results for the free stream velocity of $20 \mathrm{~ms}^{-1}$, angle of attack of $10^{\circ}$, and cylindrical rotation of $5000 \mathrm{rpm}$. Increasing the number of nodes even further would increase computational cost, albeit only slightly improve the approximation. Decreasing the number of nodes, on the other hand, would jeopardise the approximation.

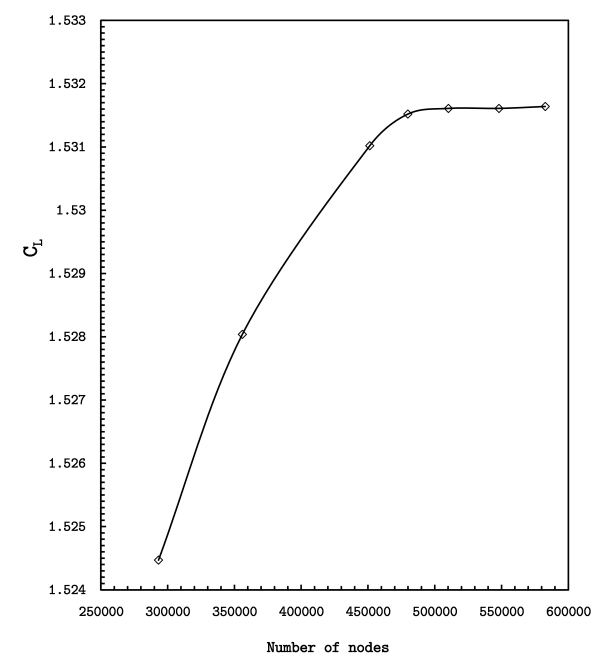

Figure 8. Grid validation test for the lift co-efficient $C_{L}$.

It is not the purpose of this paper to characterize the boundary layer. Yet, we focus on the changes in the lift and drag force due to the boundary layer development. Potential future extension of the 
current study is to account for the FSI effect and, thereby, analyse the structural vibrations to fluid flow and cylindrical rotation.

\section{Results}

Lift and drag coefficients of symmetric NACA 0021 and asymmetric NACA 23018 aerofoil with a cylinder at their leading edge at three different Reynolds numbers and six different velocity ratios are presented. The computational setup for this study was published in 2018 [40].

\subsection{Investigation on a symmetric aerofoil: NACA 0021}

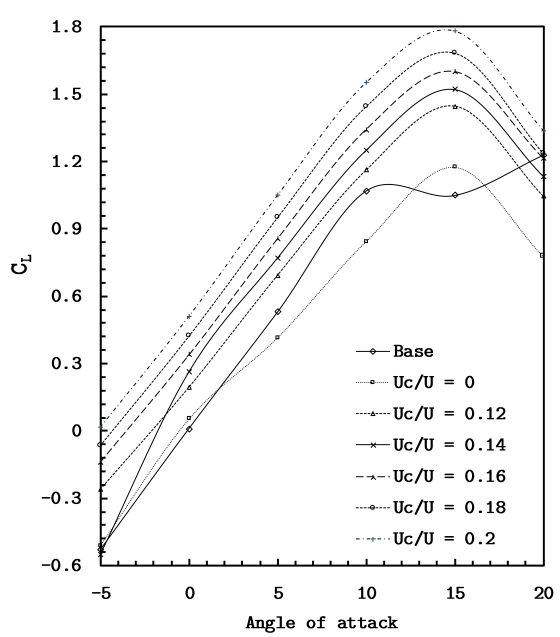

(i) Computational

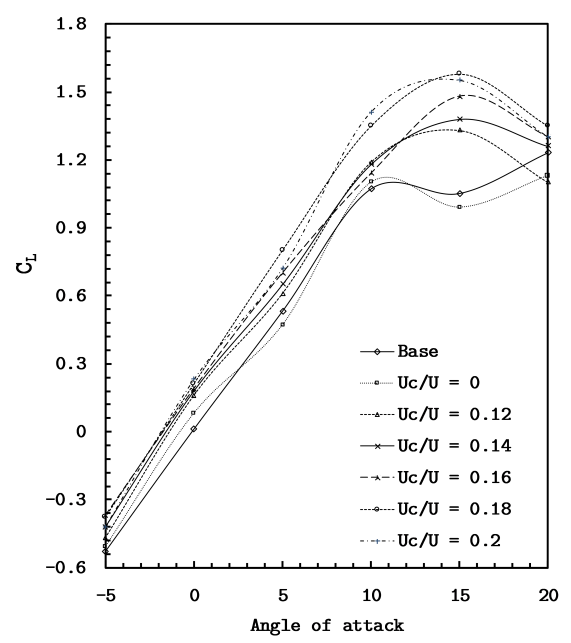

(ii) Experimental

(a) Air velocity, $v_{f}=20 \mathrm{~ms}^{-1}$ and corresponding Reynolds number, $R_{e}=2 \times 10^{5}$

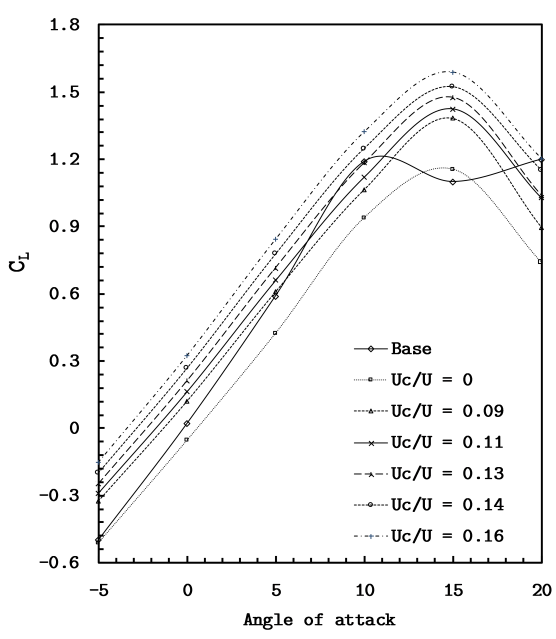

(i) Computational

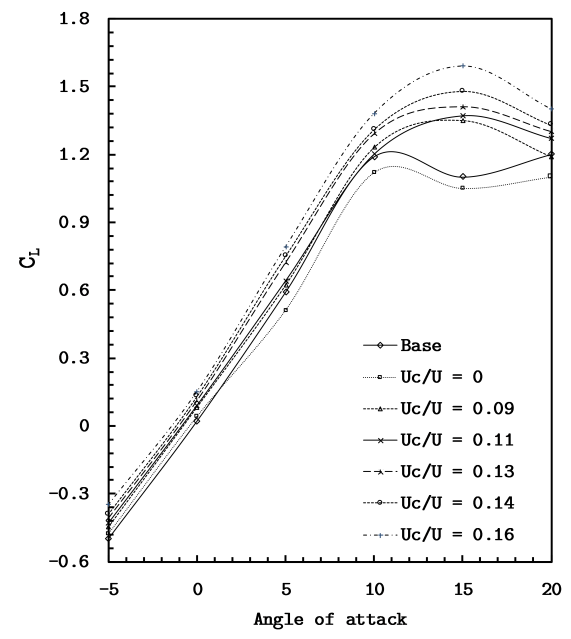

(i) Experimental

(b) Air velocity, $v_{f}=25 \mathrm{~ms}^{-1}$ and corresponding Reynolds number, $R_{e}=2.5 \times 10^{5}$

Figure 9. The relationship between the coefficient of lift $\left(C_{L}\right)$ and Angle of attack (AOA) for a base NACA 0021 and a modified NACA 0021 aerofoils.

Figure-9 represents the computational and experimental analysis of the relationship between the coefficient of lift $\left(C_{L}\right)$ and an angle of attack (AOA) for a base NACA 0021, and a modified NACA 0021 aerofoils. In this figure, numerical and experimental studies are illustrated at two different Reynolds numbers $\left(R_{e}\right) 2 \times 10^{5}$ and $2.5 \times 10^{5}$. For each case, the incorporation of the cylinder at the leading edge induces an increment in maximum lift coefficient and stall angle at all velocity ratios. At a zero velocity 
ratio, the performance degrades compared to the base aerofoil case. The reason is simple: since there is no rpm, there is no momentum injection. Therefore, the clearance between the cylinder and the leading edge causes the lift to decrease. The drop in the lift coefficient beyond a certain angle is due to a flow separation. From Figure-9 it is clear that the basic NACA 0021 aerofoil stalls at $10^{\circ}$ AOA. An addition of cylinders at the leading edge causes a gain in stalling angle when it starts rotating and it is postponed by $5^{\circ}$. Gain in $C_{L_{\max }}$ is achieved with the addition of a cylinder at the leading edge; as the rotation increases, the injection of momentum into the upper surface also increases.

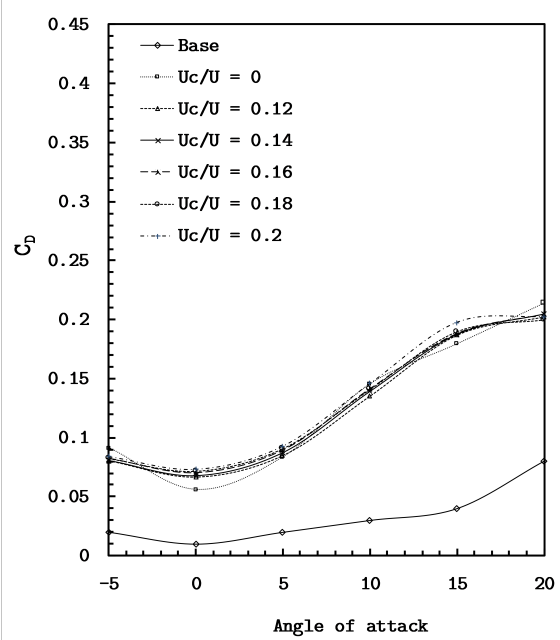

(i) Computational

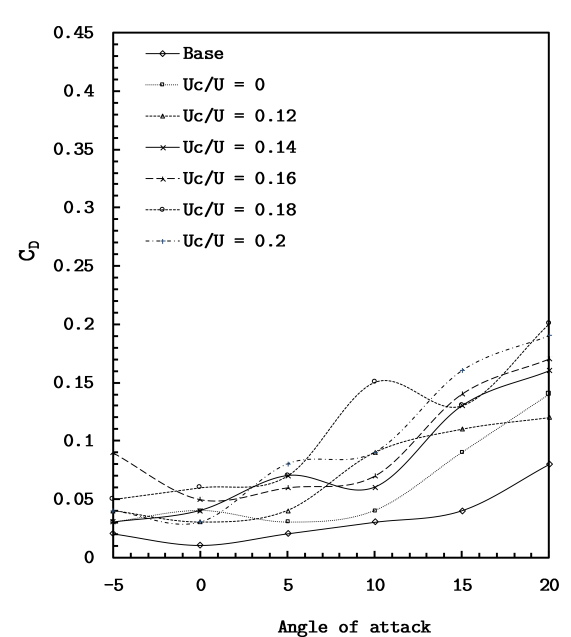

(ii) Experimental

(a) Air velocity, $v_{f}=20 \mathrm{~ms}^{-1}$ and corresponding Reynolds number, $R_{e}=2 \times 10^{5}$

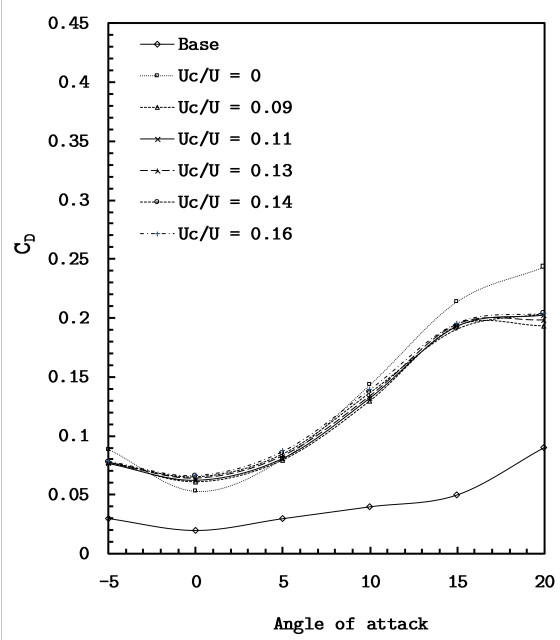

(i) Computational

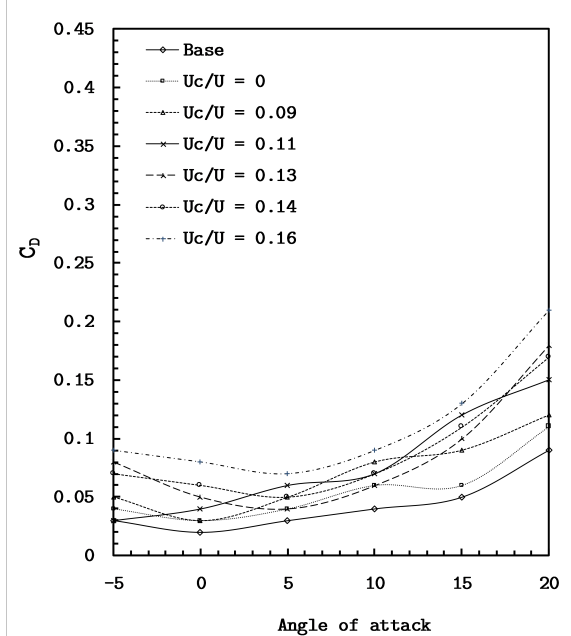

(i) Experimental

(b) Air velocity, $v_{f}=25 \mathrm{~ms}^{-1}$ and corresponding Reynolds number, $R_{e}=2.5 \times 10^{5}$

Figure 10. The relationship between the coefficient of drag $\left(C_{D}\right)$ and Angle of attack (AOA) of base NACA 0021 \& modified NACA 0021 aerofoils.

In Figure-10, the observed drag coefficient shows mixed behaviour ,for which a uniform conclusion cannot be drawn, unlike in case of the behaviour of lift coefficient. This behaviour of drag coefficient is probably due to the increasing region of separated flow over the wing surface. Here, it is clear that an addition of a cylinder at the leading-edge causes an increase in drag coefficient and it remains almost constant at all rpm i.e., drag coefficient remains within 0.20 to 0.21 except at $0 \mathrm{rpm}$. However, in the experimental study, we observed that the drag coefficient remains within 0.13 to 0.21 . A wider range of variation in drag co-efficient was observed in the experimental analysis compared to 
the computational analysis due to the presence of vibration of the cylinder in the experimental analysis. Due to the effect of vibration, the cylinder oscillated at an irregular pattern resulting in the increment of variation of the drag co-efficient. The numerical analysis was free from the effect of vibration and thus the graph of drag coefficient did not vary as much as the velocity ratio changed. The detailed analysis of the increment of $C_{L_{\max }}$ and stall angle is presented in the following table:

Table 2. Computational and experimental result analysis by comparing the gain in $C_{L_{\max }}$ and stall angle than base aerofoil.

\begin{tabular}{c|c|cc||cc}
\hline \multirow{2}{*}{$R_{e}$} & \multirow{2}{*}{$\frac{U_{c}}{U}$} & \multicolumn{2}{|c||}{ Numerical } & \multicolumn{2}{c}{ Experimental } \\
\cline { 3 - 6 } & & $\begin{array}{c}\text { Gain in } C_{L_{\max }} \\
\text { than base aerofoil }\end{array}$ & $\begin{array}{c}\text { Gain in stall angle } \\
\text { than base aerofoil }\end{array}$ & $\begin{array}{c}\text { Gain in } C_{L_{\max }} \\
\text { than base aerofoil }\end{array}$ & $\begin{array}{c}\text { Gain in stall angle } \\
\text { than base aerofoil }\end{array}$ \\
\hline \multirow{5}{*}{$2 \times 10^{5}$} & 0 & $-5.98 \%$ & $0 \%$ & $-1.82 \%$ & $0 \%$ \\
& 0.12 & $13.68 \%$ & $50 \%$ & $8.18 \%$ & $50 \%$ \\
& 0.14 & $17.95 \%$ & $50 \%$ & $13.63 \%$ & $50 \%$ \\
& 0.16 & $26.50 \%$ & $50 \%$ & $11.82 \%$ & $50 \%$ \\
& 0.18 & $35.04 \%$ & $50 \%$ & $22.73 \%$ & $50 \%$ \\
& 0.2 & $32.48 \%$ & $50 \%$ & $31.82 \%$ & $50 \%$ \\
\hline \multirow{5}{*}{$2.5 \times 10^{5}$} & 0 & $-3.58 \%$ & $0 \%$ & $-8.33 \%$ & $0 \%$ \\
& 0.09 & $15.25 \%$ & $50 \%$ & $12.50 \%$ & $50 \%$ \\
& 0.11 & $19.17 \%$ & $50 \%$ & $14.17 \%$ & $50 \%$ \\
& 0.13 & $23.33 \%$ & $50 \%$ & $17.50 \%$ & $50 \%$ \\
& 0.14 & $26.67 \%$ & $50 \%$ & $23.33 \%$ & $50 \%$ \\
& 0.16 & $32.42 \%$ & $50 \%$ & $32.50 \%$ & $50 \%$ \\
\hline
\end{tabular}

From the Table-2, it is clear that for NACA 0021 aerofoil the computational gain is higher than the experimental gain for all the velocity ratios, except for case of the zero velocity ratio. Noteworthy, the numerical study does not include the effect of fluid-structure interaction (FSI) [41-51]. Thereby, the associated vibration is neglected in the numerical results. In the experimental investigation, there was an adverse effect of vibration of the cylinder. For this reason, the cylinder oscillated and, as a result, the amount of generated lift was reduced. In the computational analysis, the vibrational effect was not considered. Therefore, the experimental gain was less than the computational gain. However, at a higher velocity ratio $(=0.2)$ the adverse effect of vibration of the cylinder is lower. Therefore, the experimental gain is almost the same as the computational gain.

\subsection{Investigation on an asymmetric aerofoil: NACA 23018}

Figure-11 represents the relationship between the coefficient of lift $\left(C_{L}\right)$ and an angle of attack (AOA) for a base NACA 23018 \& a modified NACA 23018 aerofoils from the computational and experimental analysis. Here, we observed that the incorporation of a cylinder at the leading edge causes an increment in maximum lift coefficient at all velocity ratios, except for the zero velocity ratio case. At a zero velocity ratio, the performance degrades compared to the base aerofoil. Without rpm, there is no momentum injection. Therefore, the clearance between the cylinder and the leading edge causes the lift to decrease. The latter is driven by the flow separation. In addition, $C_{L}$ degrades more than the base aerofoil for the negative angle of attacks. The basic NACA 23018 aerofoil stalls at $15^{\circ}$ AOA in numerical study, albeit a $12^{\circ} \mathrm{AOA}$ in the experiment. In numerical study, the leading edge does not cause further gain in stalling angle when it starts rotating. However, in the experiment we observed that the leading edge causes a further gain in stalling angle by $3^{\circ} \mathrm{AOA}$ when the rotation starts. Gain in $C_{L_{\max }}$ is achieved with the addition of cylinder at the leading edge. With the increase in the rotation, the injection of momentum to the upper surface increases. 


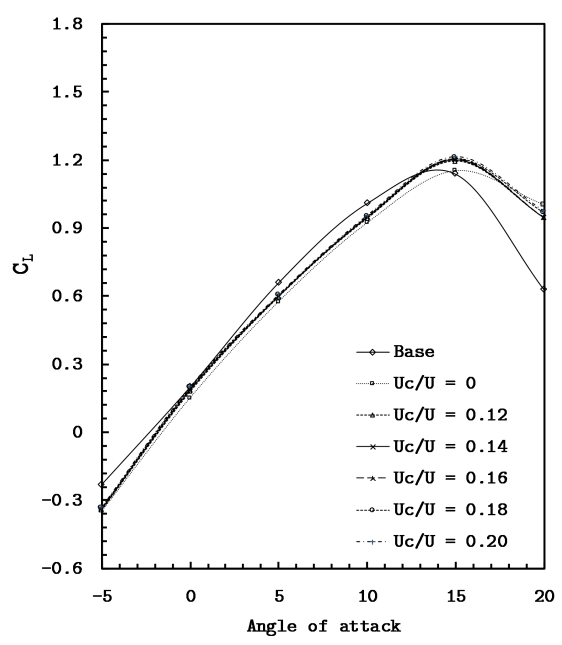

(i) Computational

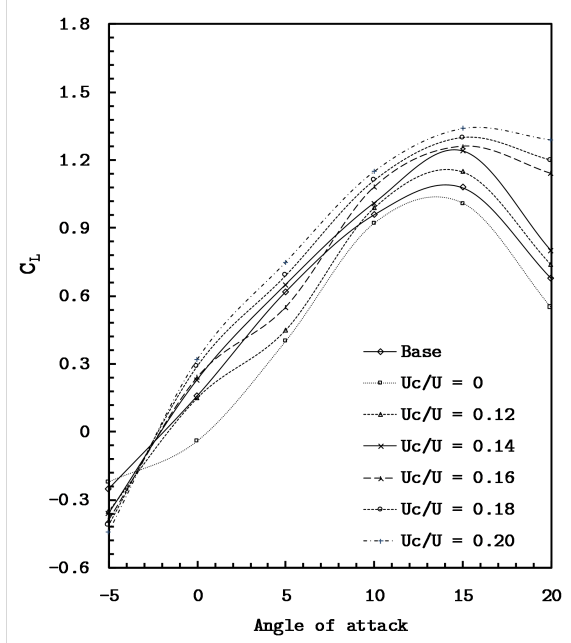

(ii) Experimental

(a) Air velocity, $v_{f}=20 \mathrm{~ms}^{-1}$ and corresponding Reynolds number, $R_{\mathcal{e}}=2 \times 10^{5}$

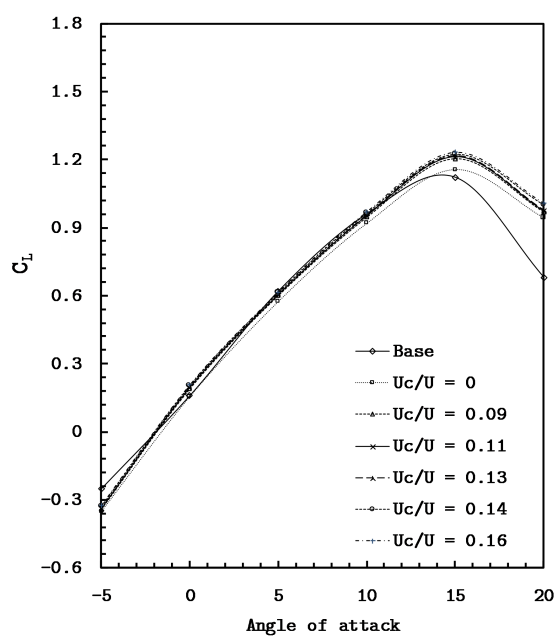

(i) Computational

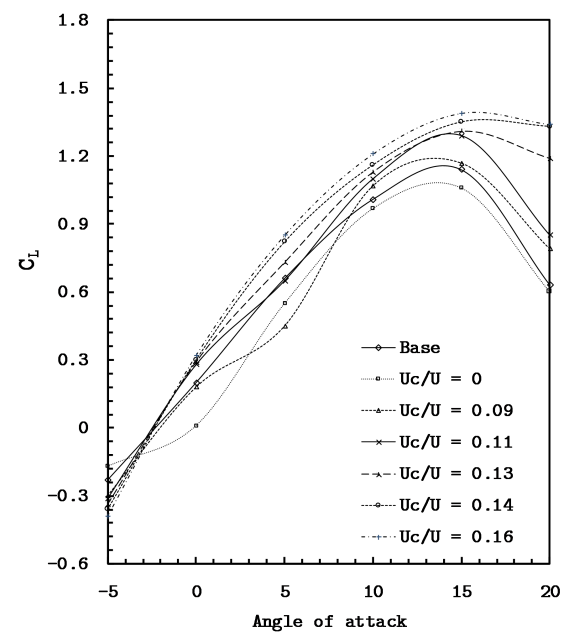

(i) Experimental

(b) Air velocity, $v_{f}=25 \mathrm{~ms}^{-1}$ and corresponding Reynolds number, $R_{\mathcal{e}}=2.5 \times 10^{5}$

Figure 11. Relationship between the coefficient of lift $\left(C_{L}\right)$ and Angle of attack (AOA) for a base NACA 23018 \& a modified NACA 23018 aerofoils.

In Figure-12, the incorporation of a cylinder at the leading edge causes an increment in maximum drag coefficient and stall angle at all velocity ratios. In numerical simulations, the leading-edge introduces the increment in drag coefficient compared to the base aerofoil of up to $15^{\circ} \mathrm{AOA}$. But at $20^{\circ}$ $\mathrm{AOA}$, the $C_{D}$ decreases compared to the base aerofoil and it remains almost constant at all velocity ratios, i.e. drag coefficient remains around 0.27 at $R_{e}=2 \times 10^{5}$, and 0.25 , except for the case of the zero velocity ratio. For the base aerofoil, the flow separation started around $15^{\circ} \mathrm{AOA}$, and thus the drag co-efficient increased at a much steeper slope after $15^{\circ}$ AOA. For the modified aerofoil, the drag co-efficient slope was less steep than in the base aerofoil case because of the delay in flow separation. Due to the presence of the rotating cylinder, the $C_{D}$ of modified aerofoils was higher than in the base aerofoil case before stall angle since it was obstructing the airflow. But as the angle of attack gradually increased, the $C_{D}$ in the base aerofoil increased sharply compared to the modified aerofoils. On other hand, in the experiment, the leading-edge causes an increment in drag coefficient compared to the base aerofoil at all velocity ratios and remains between 0.35 to 0.4 . A wide variation of the $C_{D}$ was observed in the experimental analysis because of the irregular oscillation of the vibrating cylinder due to its rotation. In the asymmetric aerofoil, the gap between the cylinder and the aerofoil was also 
asymmetric. When the cylinder vibrated, the more irregular gap was created in the aerofoil. Thus, this resulted in the higher increment of the drag co-efficient in the experimental analysis than in the computational analysis.

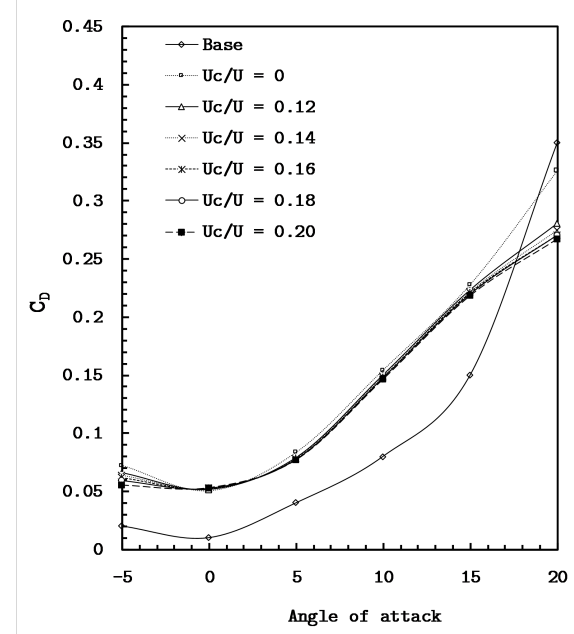

(i) Computational

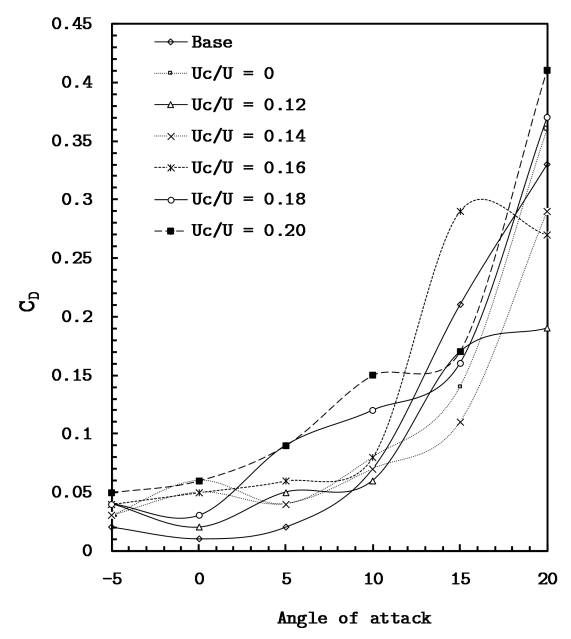

(ii) Experimental

(a) Air velocity, $v_{f}=20 \mathrm{~ms}^{-1}$ and corresponding Reynolds number, $R_{e}=2 \times 10^{5}$

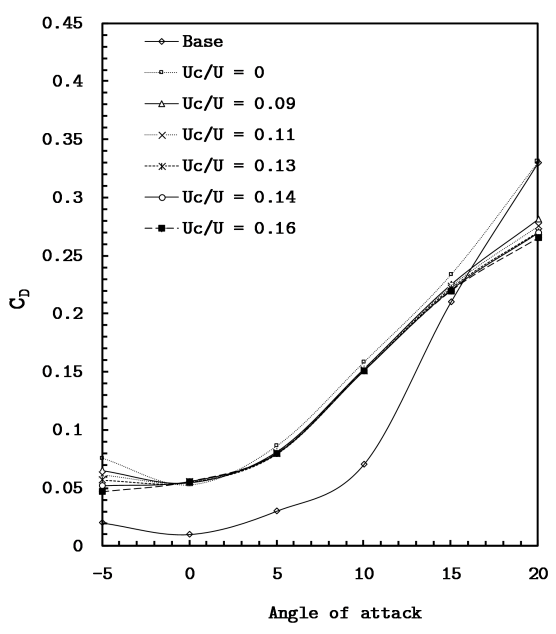

(i) Computational

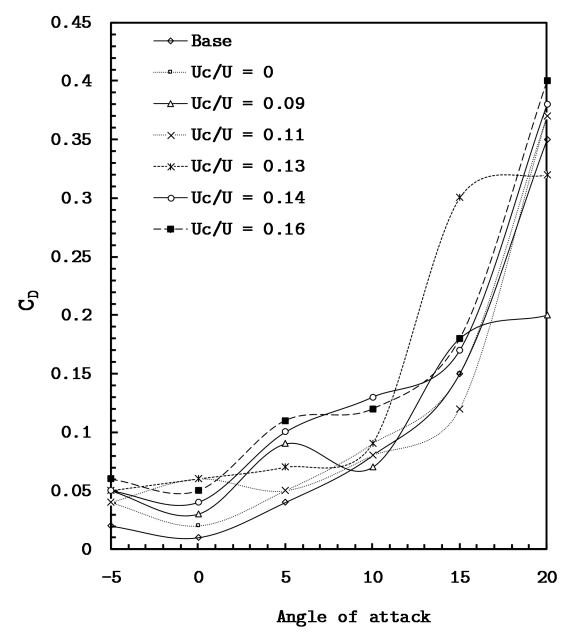

(i) Experimental

(b) Air velocity, $v_{f}=25 \mathrm{~ms}^{-1}$ and corresponding Reynolds number, $R_{e}=2.5 \times 10^{5}$

Figure 12. Relationship between the coefficient of drag $\left(C_{D}\right)$ and Angle of attack (AOA) for a base NACA 23018 \& a modified NACA 23018 aerofoils.

The detailed analysis of an increment of $C_{L_{\max }}$ and stall angle is presented in the Table-3. Here, it is clear that for NACA 23018 aerofoil the computational gain is higher than in the experimental gain for all low velocity ratios (below 0.1). In the experimental investigation, there was an adverse effect of vibration of the cylinder. Therefore, the cylinder oscillated stronger and, as a result, the amount of generated lift was reduced. In the computational analysis, the vibrational effect was not considered. Thus, the experimental gain was smaller than the computed gain. However, at a higher velocity ratio $(>0.1)$ the adverse effect of vibration of the cylinder is smaller due to the asymmetry of the aerofoil. Therefore, an increase in the experimental gain is higher than that in the computational gain. 
Table 3. Computational and experimental result analysis by comparing the gain in $C_{L_{\max }}$ and stall angle than base aerofoil.

\begin{tabular}{c|c|cc||cc}
\hline \multirow{2}{*}{$R_{e}$} & \multirow{2}{*}{$U_{c}$} & \multicolumn{2}{|c||}{ Numerical } & \multicolumn{2}{c}{ Experimental } \\
\cline { 3 - 6 } & & $\begin{array}{c}\text { Gain in } C_{L_{\max }} \\
\text { than base aerofoil }\end{array}$ & $\begin{array}{c}\text { Gain in stall angle } \\
\text { than base aerofoil }\end{array}$ & $\begin{array}{c}\text { Gain in } C_{L_{\max }} \\
\text { than base aerofoil }\end{array}$ & $\begin{array}{c}\text { Gain in stall angle } \\
\text { than base aerofoil }\end{array}$ \\
\hline \multirow{5}{*}{$2 \times 10^{5}$} & 0 & $1.12 \%$ & $0 \%$ & $-6.48 \%$ & $0 \%$ \\
& 0.12 & $4.79 \%$ & $0 \%$ & $6.48 \%$ & $0 \%$ \\
& 0.14 & $5.2 \%$ & $0 \%$ & $14.81 \%$ & $0 \%$ \\
& 0.16 & $5.75 \%$ & $0 \%$ & $16.67 \%$ & $20 \%$ \\
& 0.18 & $6.07 \%$ & $0 \%$ & $20.37 \%$ & $20 \%$ \\
& 0.2 & $6.63 \%$ & $0 \%$ & $24.07 \%$ & $20 \%$ \\
\hline \multirow{5}{*}{$2.5 \times 10^{5}$} & 0 & $3.31 \%$ & $0 \%$ & $-7.02 \%$ & $0 \%$ \\
& 0.09 & $7.58 \%$ & $20 \%$ & $2.63 \%$ & $20 \%$ \\
& 0.11 & $8.28 \%$ & $20 \%$ & $13.16 \%$ & $20 \%$ \\
& 0.13 & $8.82 \%$ & $20 \%$ & $14.91 \%$ & $20 \%$ \\
& 0.14 & $9.35 \%$ & $20 \%$ & $18.42 \%$ & $20 \%$ \\
\hline
\end{tabular}

5.3. Comparison of gain in $C_{L_{\max }}$ for NACA 0021 and NACA 23018

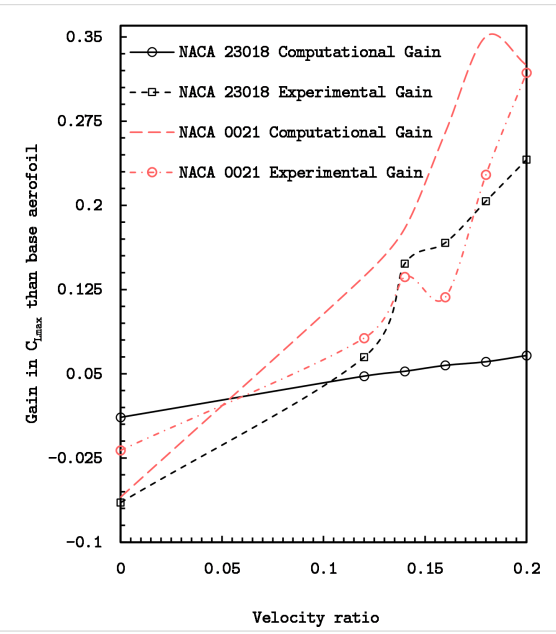

(a)

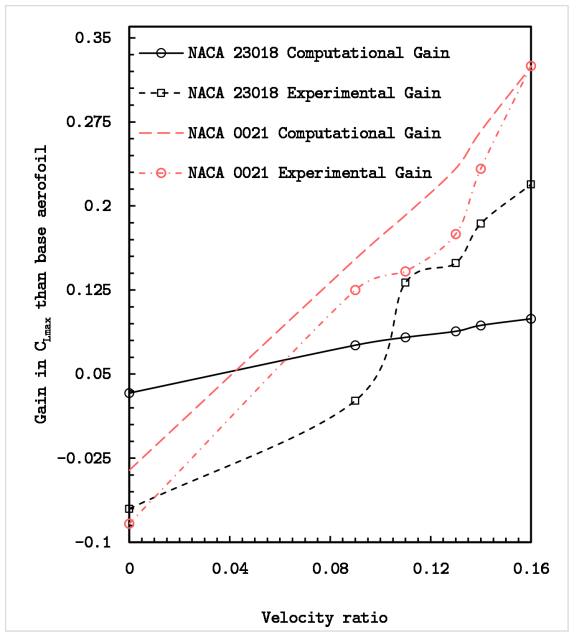

(b)

Figure 13. Gain in $C_{L_{\max }}$ than base aerofoil vs velocity ratio curve for NACA 23018 and NACA 0021 at (a) $R_{e} \mathrm{No}=2 \times 10^{5}$, and (d) $R_{e} \mathrm{No}=2.5 \times 10^{5}$.

Figure-13 represents the gain in $C_{L_{\max }}$ with respect to base aerofoil vs. velocity ratio curve for both computational and experimental analysis. For NACA 0021 aerofoil, it is observed from the figure that for velocity ratios near zero, a noticeable loss in $C_{L_{\max }}$ occurred as opposed to the base aerofoil case. At velocity ratios around 0.05 , gain in $C_{L_{\max }}$ was noticeable. For $\mathrm{R}_{e}$ No. $2 \times 10^{5}$, the experimental gain was higher than the computed gain at the velocity ratio near zero. Yet, as the velocity ratio increased, the computational gain also increased more than the experimental gain. For $\mathrm{R}_{e}$ No. $2.5 \times 10^{5}$, the experimental gain was always lower than the computational gain in $C_{L_{\max }}$ compared to the base aerofoil. But, at $\frac{U_{C}}{U}=0.16$, the difference between them became negligible. For NACA 23018 aerofoil, it is observed from the figure that for velocity ratios near zero, a noticeable loss occurred in $C_{L_{\max }}$ compared to the base aerofoil in the experimental analysis. At velocity ratios around 0.1 , gain in $C_{L_{\max }}$ was noticeable. For $\mathrm{R}_{e}$ No. $2 \times 10^{5}$, experimental gain was lower than the computational gain at the velocity ratio near zero. But as the velocity ratio increased, the experimental gain increased more than the computational gain near velocity ratio 0.1 . For $\mathrm{R}_{e}$ No. $2.5 \times 10^{5}$, the experimental gain was lower than the computational gain in $C_{L_{\max }}$ compared to the base aerofoil up to velocity ratio of about 0.1 . However, at $\frac{U_{C}}{U}=0.16$ the difference between them increases. The asymmetric gap 
between the rotating cylinder and the NACA 23018 aerofoil was a significant factor in the analysis. In the computational analysis, there was no noticeable effect of increasing velocity ratios because of the irregular gap. In the experimental analysis, however, due to a rotation of the cylinder this irregularity increased, which resulted in a much steeper curve of $C_{L_{\max }}$.

\subsection{Rotational Vibration Analysis}

To analyse the effect of a rotational vibration, another configuration was tested in the wind tunnel. This configuration consisted of two rotating cylinders, each of them is $120 \mathrm{~mm}$ length. To reduce the rotational vibration, the support was provided in the middle of the wing section of length $60 \mathrm{~mm}$; the span of the wing section was $300 \mathrm{~mm}$. The base aerofoil was NACA 0021 and the experimental setup was similar to the previous investigation. Figure-4(b) represents the experimental model of the wing part used to conduct this investigation.

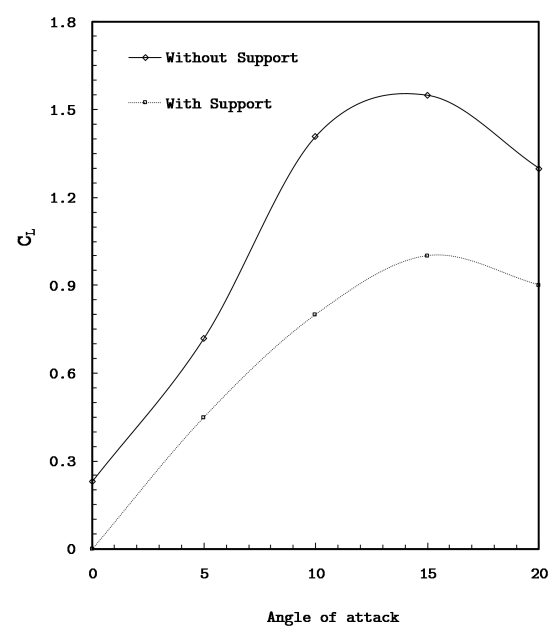

(i) $C_{L}$ vs AOA

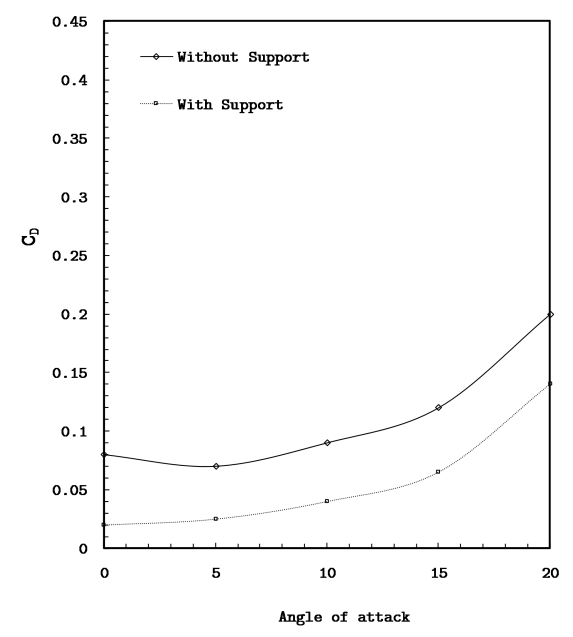

(ii) $C_{D}$ vs AOA

(a) Air velocity, $v_{f}=20 \mathrm{~ms}^{-1}$ and corresponding Reynolds number, $R_{e}=2 \times 10^{5}$

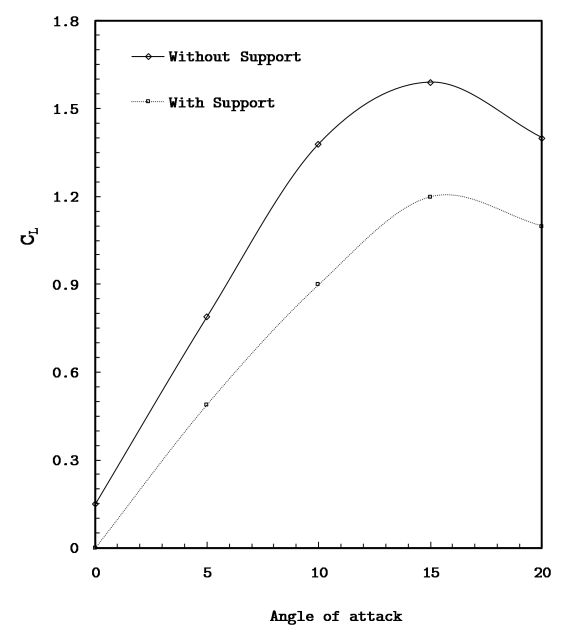

(i) $C_{L}$ vs AOA

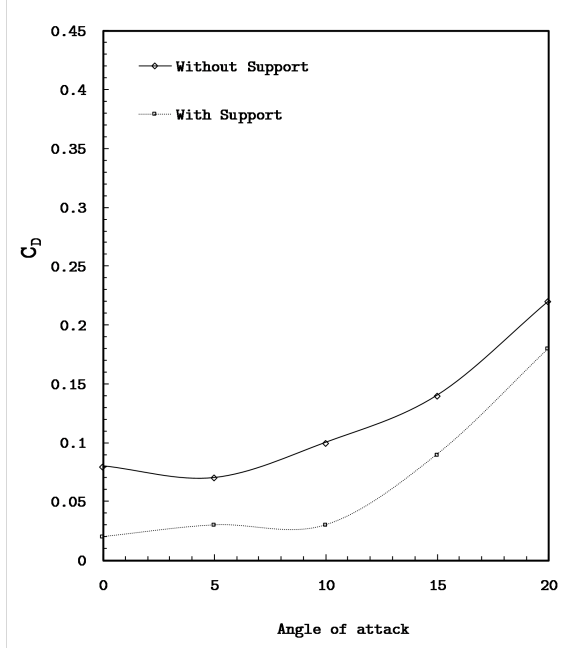

(i) $C_{D}$ vs AOA

(b) Air velocity, $v_{f}=25 \mathrm{~ms}^{-1}$ and corresponding Reynolds number, $R_{e}=2.5 \times 10^{5}$

Figure 14. Difference in the mechanism with and without support for NACA 0021 aerofoil.

Figure-14 represents the $C_{L}$ versus the angle of attack (AOA) and $C_{D}$ versus AOA curve for the modified wing with and without support mechanism. The figure illustrates that the drag is reduced more significantly in the case of the mechanism without the support compared to the modified wing 
with a support mechanism. Therefore, without a support in the middle of the cylinder, the vibrations were larger and therefore the drag was increased. The cylinder generated less oscillations for the support mechanism. The lift co-efficient was decreased to some extent too due to lower surface area for the Magnus effect. Further investigations into implications of the Magnus effect is a fruitful area for further research.

\subsection{Power Consumption Analysis}

The most eye-catching characteristics of the flow control using MSBC are lower power consumption in a spinning cylinder. Figure-15 shows the comparison between the power consumption for rotating the cylinder starting from a stationary state and to the rotational speed of $5000 \mathrm{rpm}$. From the graph it is clear that the power requirement to rotate the cylinder is negligible compared to the enhancement in the lift and stall angle.

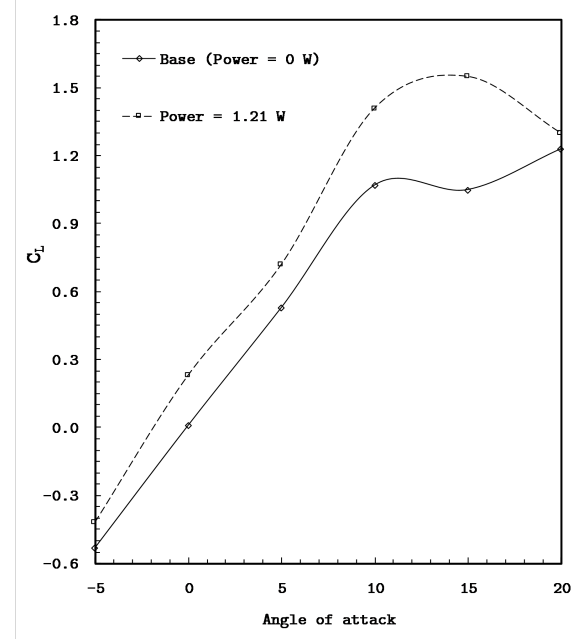

(i) NACA 0021

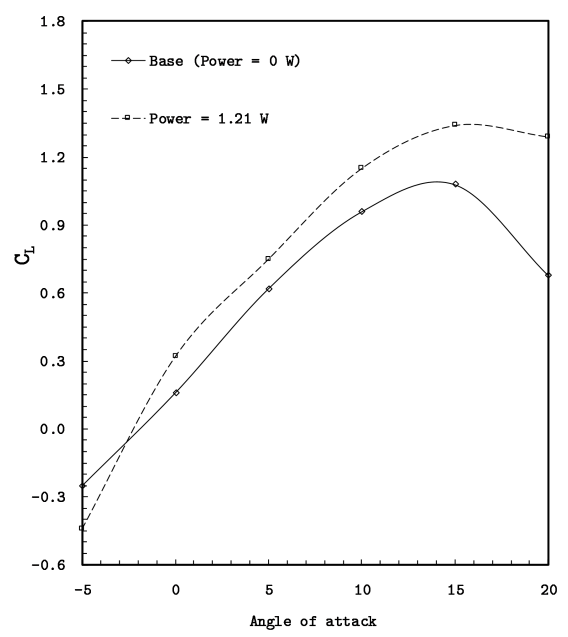

(ii) NACA 23018

(a) Air velocity, $v_{f}=20 \mathrm{~ms}^{-1}$ and corresponding Reynolds number, $R_{e}=2 \times 10^{5}$

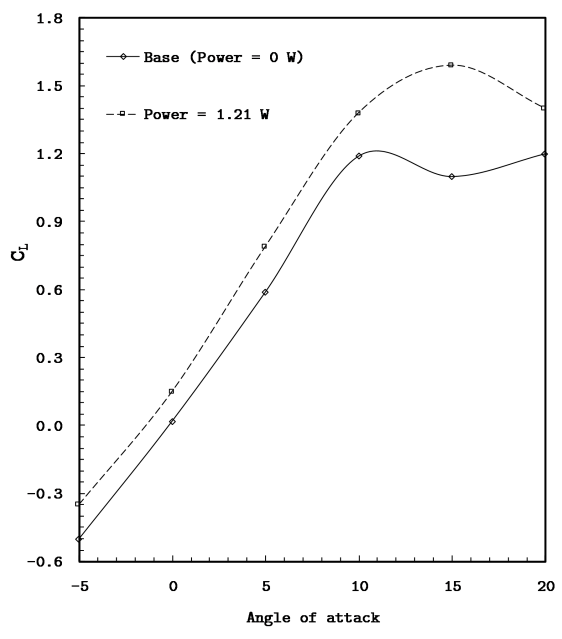

(i) NACA 0021

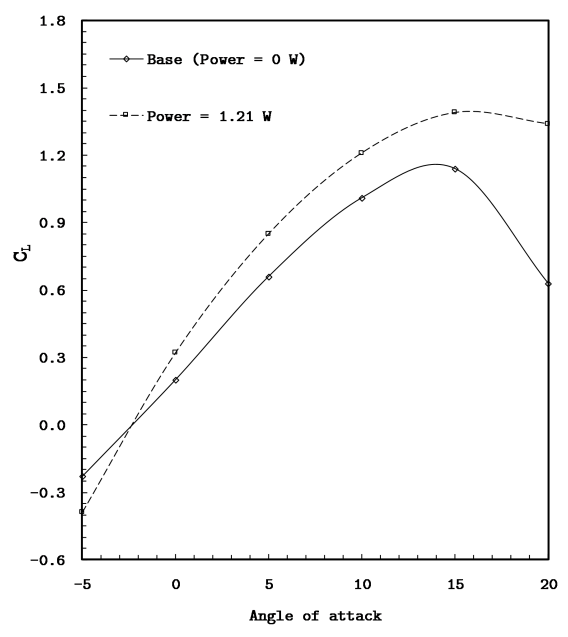

(ii) NACA 23018

(b) Air velocity, $v_{f}=25 \mathrm{~ms}^{-1}$ and corresponding Reynolds number, $R_{e}=2.5 \times 10^{5}$

Figure 15. Power requirement analysis. 
5.6. Comparison between experimental and computational analysis

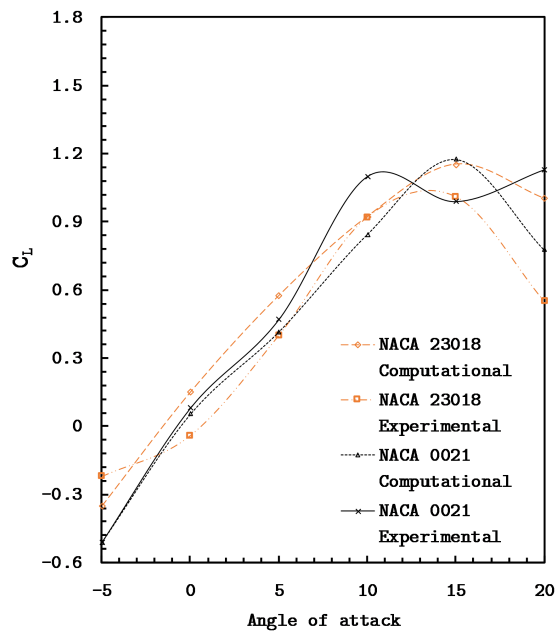

(a)

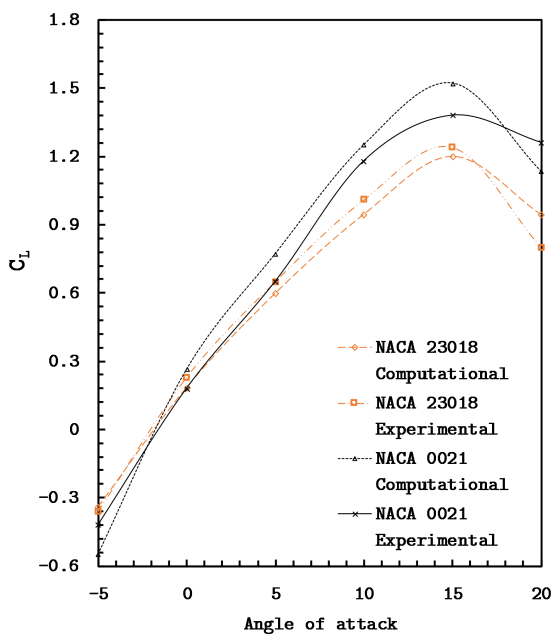

(c)

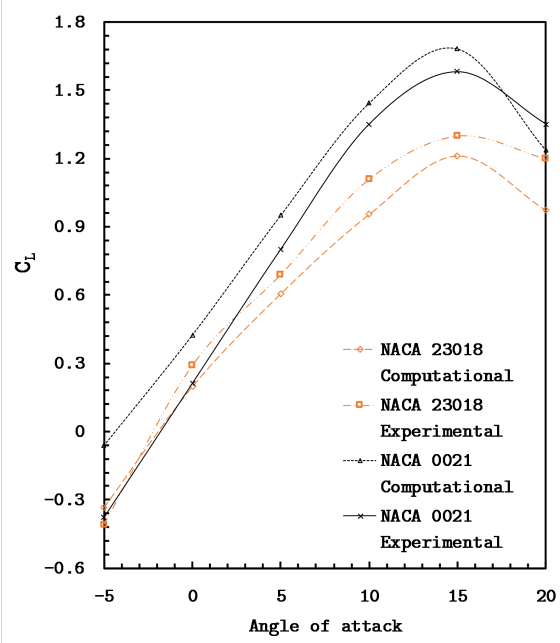

(e)

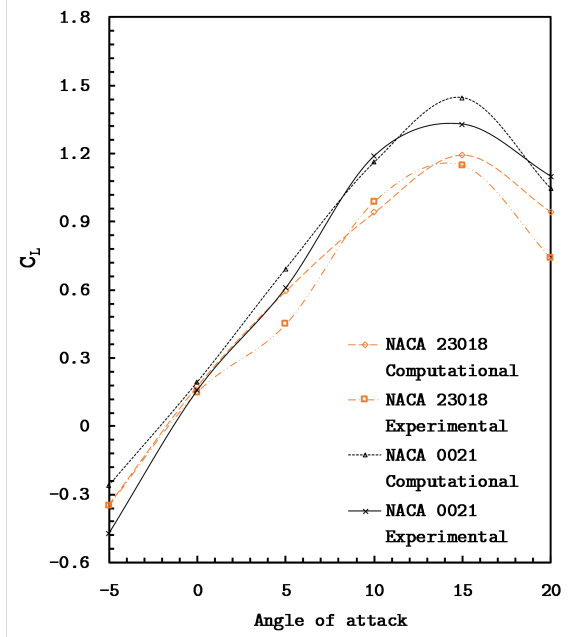

(b)

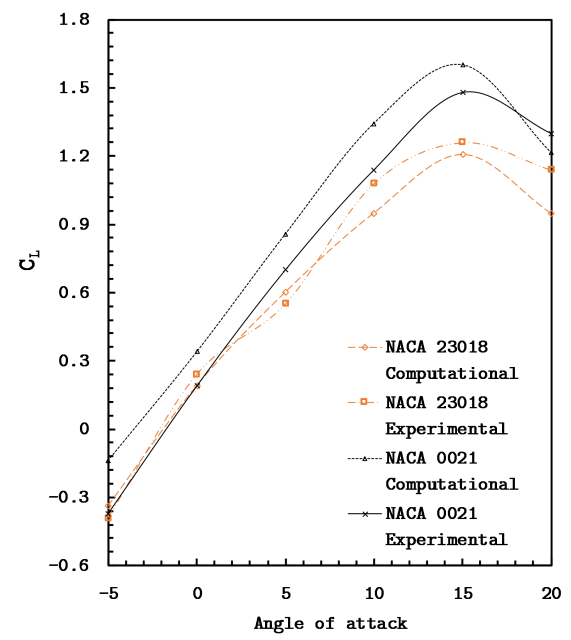

(d)

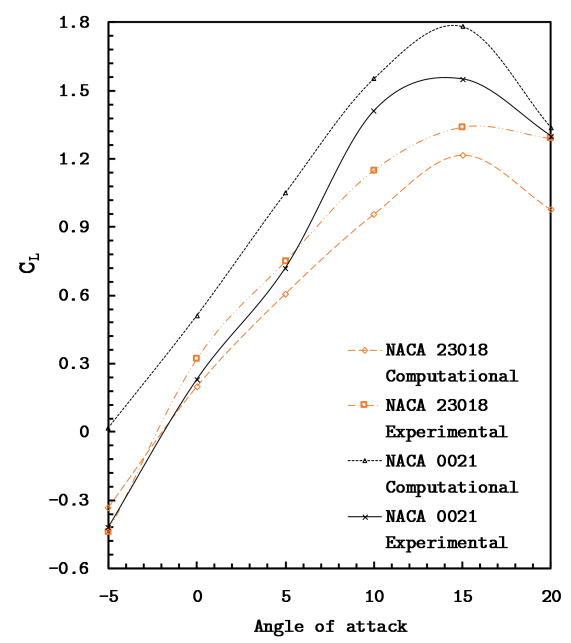

(f)

Figure 16. Computational vs. experimental analysis curve for NACA 23018 and NACA 0021 of $C_{L}$ vs Angle of attack at $R_{e}$ no. $2 \times 10^{5}$ for (a) $\frac{U_{C}}{U}=0$; (b) $\frac{U_{C}}{U}=0.12$; (c) $\frac{U_{C}}{U}=0.14$; (d) $\frac{U_{C}}{U}=0.16$; (e) $\frac{U_{C}}{U}=0.18 ;(f) \frac{U_{C}}{U}=0.2$. 


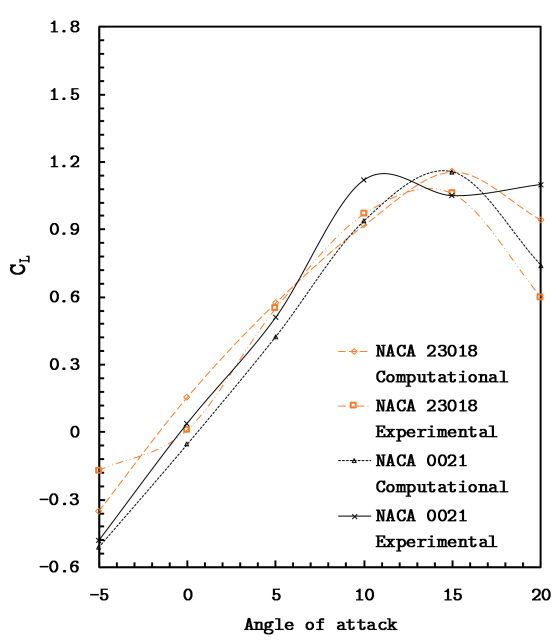

(a)

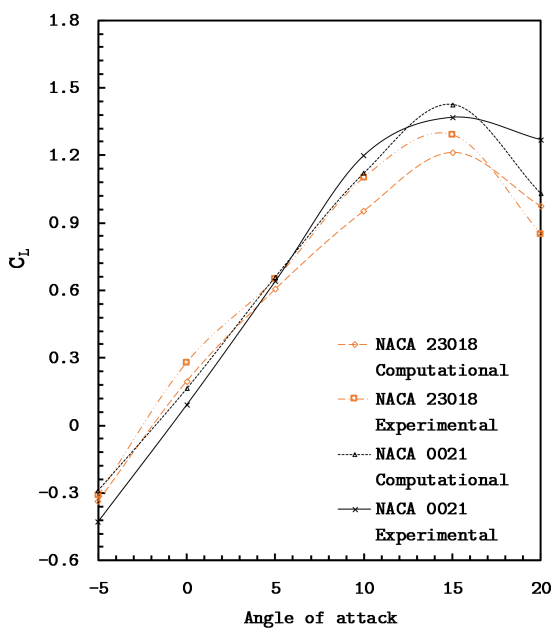

(c)

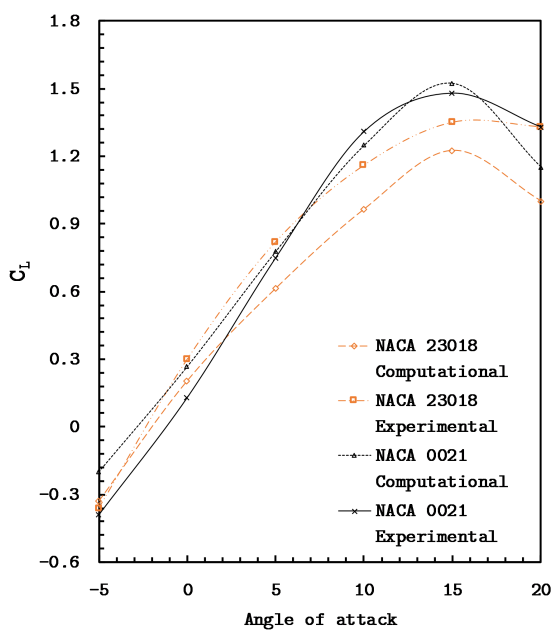

(e)

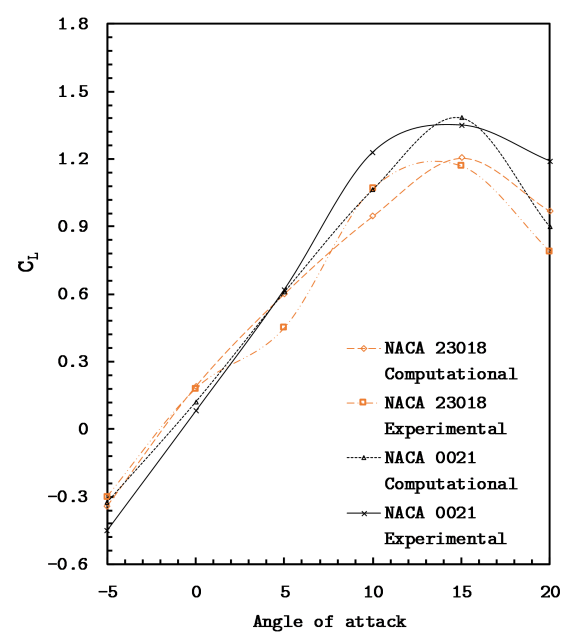

(b)

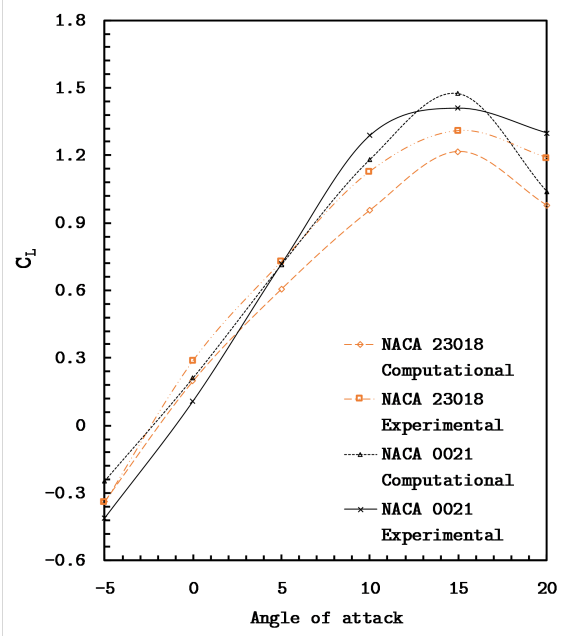

(d)

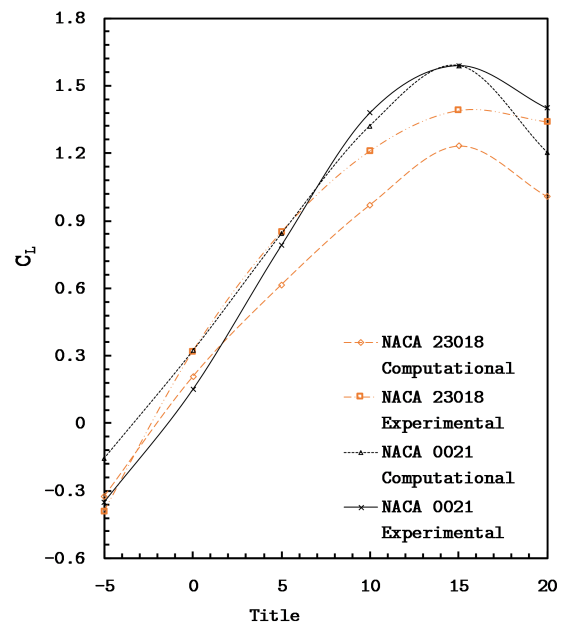

(f)

Figure 17. Computational vs. experimental analysis curve for NACA 23018 and NACA 0021 of $C_{L}$ vs Angle of attack at $R_{e}$ no. $2.5 \times 10^{5}$ for (a) $\frac{U_{C}}{U}=0$; (b) $\frac{U_{C}}{U}=0.12$; (c) $\frac{U_{C}}{U}=0.14$; (d) $\frac{U_{C}}{U}=0.16$; (e) $\frac{U_{C}}{U}=0.18 ;(f) \frac{U_{C}}{U}=0.2$. 


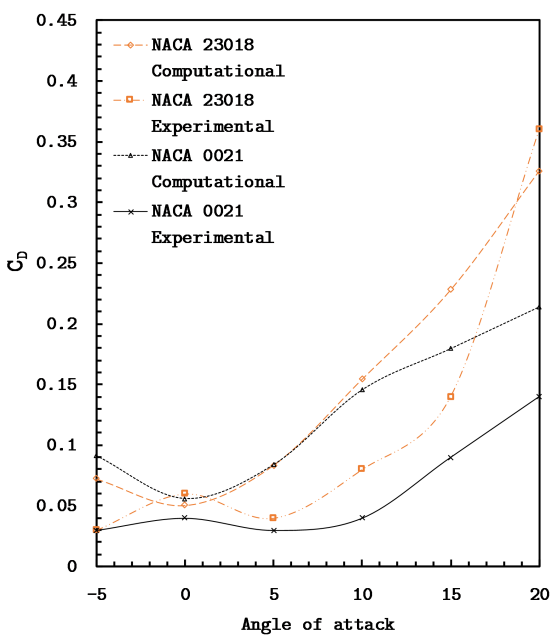

(a)

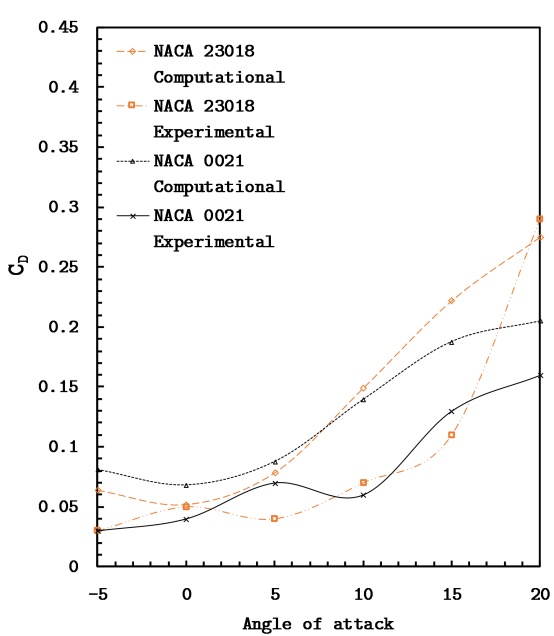

(c)

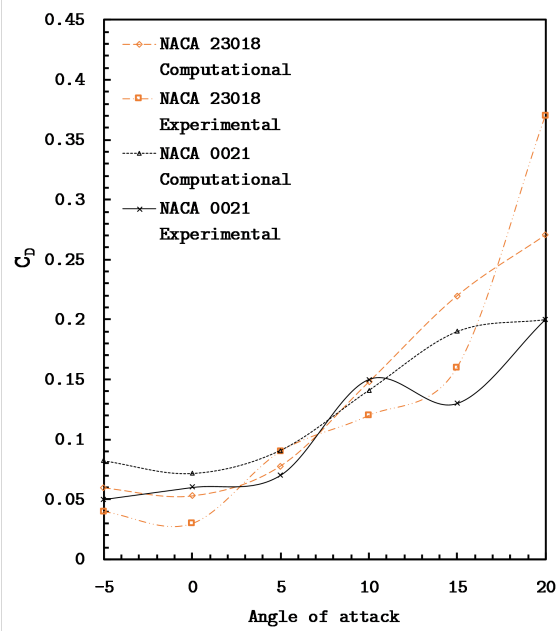

(e)

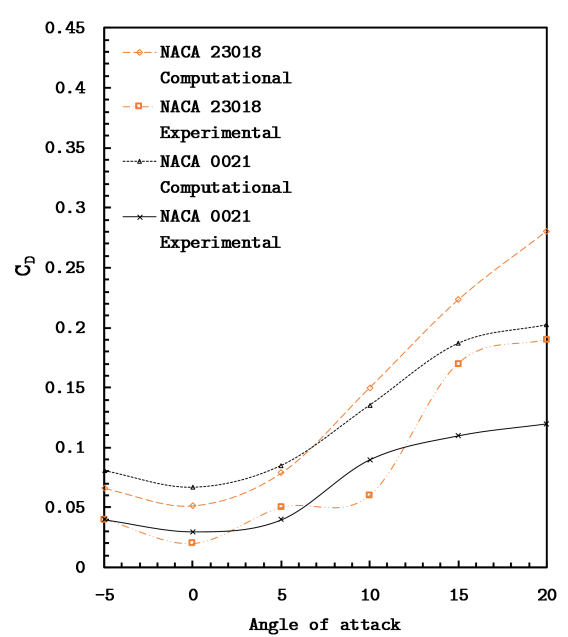

(b)

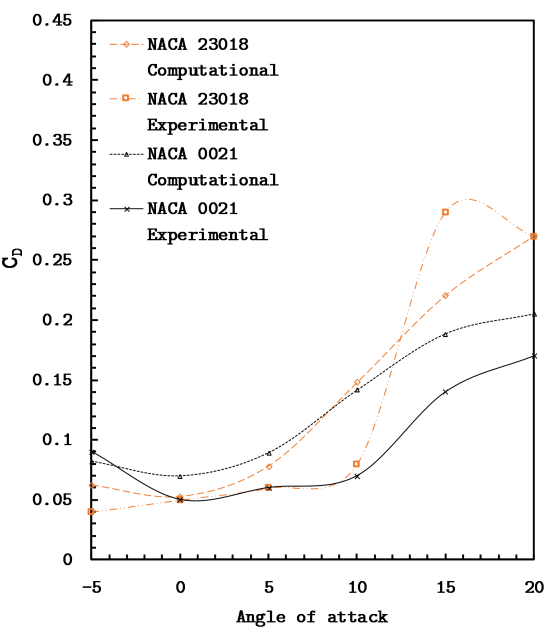

(d)

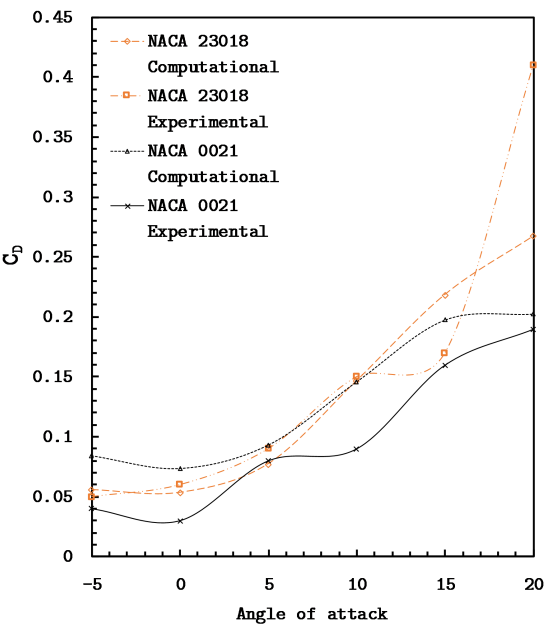

(f)

Figure 18. Computational vs. experimental analysis curve for NACA 23018 and NACA 0021 of $C_{D}$ vs Angle of attack at $R_{e}$ no. $2 \times 10^{5}$ for (a) $\frac{U_{C}}{U}=0$; (b) $\frac{U_{C}}{U}=0.12$; (c) $\frac{U_{C}}{U}=0.14$; (d) $\frac{U_{C}}{U}=0.16$; (e) $\frac{U_{C}}{U}=0.18$; (f) $\frac{U_{C}}{U}=0.2$. 


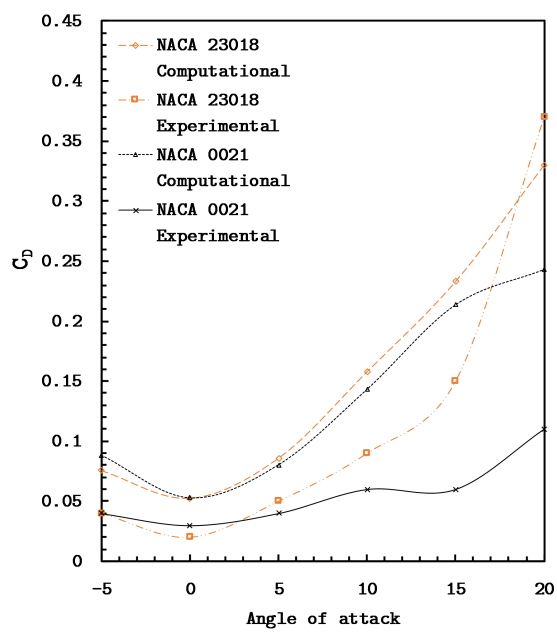

(a)

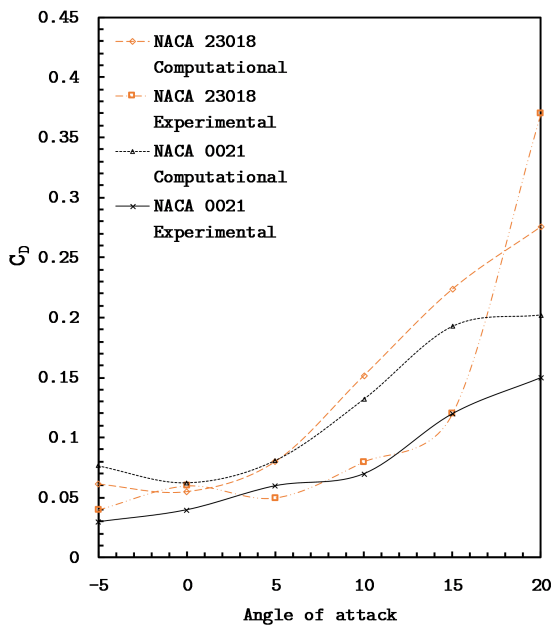

(c)

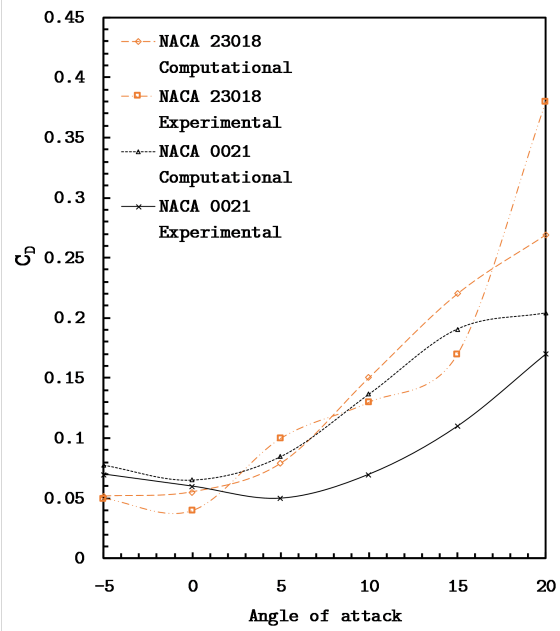

(e)

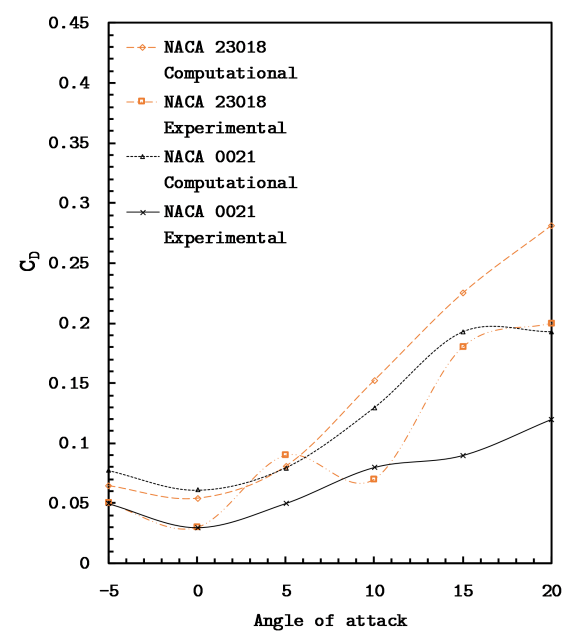

(b)

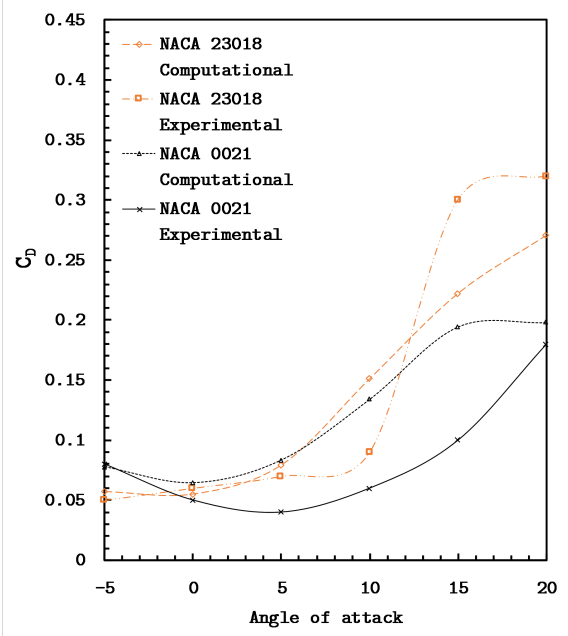

(d)

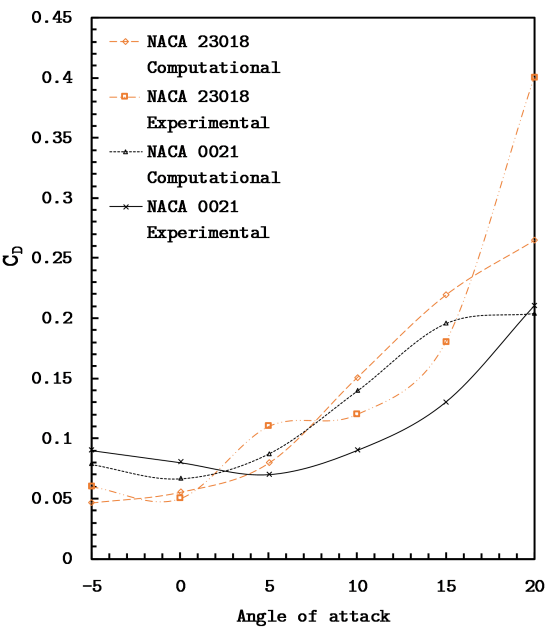

(f)

Figure 19. Computational vs. experimental analysis curve for NACA 23018 and NACA 0021 of $C_{D}$ vs Angle of attack at $R_{e}$ no. $2.5 \times 10^{5}$ for (a) $\frac{U_{C}}{U}=0$; (b) $\frac{U_{C}}{U}=0.12$; (c) $\frac{U_{C}}{U}=0.14$; (d) $\frac{U_{C}}{U}=0.16$; (e) $\frac{U_{C}}{U}=0.18$; (f) $\frac{U_{C}}{U}=0.2$. 
A comparison between the experimental and computational investigations was carried out. Figures 16-19 contrast NACA 0021 and NACA 23018. From the figure, it can be seen that the lift coefficient curve for computational and experimental analysis almost coincide with the symmetric aerofoil at lower velocity ratios. However, as the velocity ratio increases, the lift co-efficient curve increases stronger in the case of symmetric aerofoil compared to the asymmetric aerofoil. As for the drag co-efficient, both NACA 0021 and NACA 23018 showed almost similar trend in increment. Yet, the drag co-efficient of symmetric NACA 0021 aerofoil was below the drag co-efficient of asymmetric NACA 23018 aerofoil. In addition, the drag coefficient was smaller in the experimental analysis than in the computational analysis. The reason is the different size of the domain: the domain selected for the computational analysis was much larger than the domain area for experimental analysis. Thereby, the total drag in the computational analysis was larger than in experimental analysis.

\section{Discussion}

Simulation results presented in this study are in line with the experimental results in almost all cases. That is, the results validate the experimental data. At all velocities maximum lift coefficient increases with the rpm. The same does not hold for the drag coefficients since their variation is irregular. The drag coefficient remains between 0.13 and 0.24 in most cases. At $20 \mathrm{~ms}^{-1}$ stall angle increases at all $\mathrm{rpm}$ at a constant rate, except for the zero rpm case. More specifically, the value of the lift coefficient is driven by the delay in flow separation at higher angles of attack in view of momentum injection by the leading edge cylinder. The Magnus effect of the leading edge cylinder is a second major contributor to the improvement of the overall aerofoil coefficient of lift. The leading edge rotating cylinder acts like the vane less compressor, compressing the air in the channel and supplying the high pressure air to the bottom surface and the front of an aerofoil, which in turn contributes marginally to the improvement in aerofoil performance. This preliminary study indicates the feasibility of practical implementation of leading edge cylinders for thick aerofoil in aviation, wind turbine, and other applications. The use of the above-mentioned modifications to the aerofoil would add further layer of complexity for the structural health monitoring (SHM) system due to the addition of cylinder-driven vibrations [41-51].

\section{Conclusions}

The numerical and experimental investigation of the modified NACA 0021 and NACA 23018 aerofoils with leading edge rotating cylinder revealed that the performance of the modified aerofoil is superior to the base aerofoil for velocity ratios less than 1.0. As opposed to previous studies, study presented results only for higher velocity ratios. In the experimental analysis, there were large adverse effects of vibrations on the performance of the aerofoil. The oscillations were generated on the cylinder, and thereby, there was a wide variation of results for $C_{L}$ and $C_{D}$ compared to the computational analysis. The effect of vibration on the clearance between the rotating cylinder and the aerofoil surface also played a vital role in assessing the performance of the modified aerofoil. The performance of the modified NACA 0021 aerofoil was superior to the modified NACA 23018 aerofoil with the asymmetric clearance of NACA 23018 being a contributing factor. The study revealed that the presence of the support mechanism is more efficient in reducing the drag relative to rotating the cylinder without the support mechanism. However, due to the reduction of the moving surface area the lift decreased. More analysis is required to investigate the benefits of the support mechanism. The technique should aim at keeping the amount of moving surface area the same while providing a support, ensuring a decrease in the vibrations of a cylinder. The associated lower power consumption to rotate the cylinder constitutes an additional advantage.

\section{References}

1. Clancy, L. J. Aerodynamics, $1^{\text {st }}$ ed., Pitman Publishing Limited, 1980, pp. 112-113.

2. Anderson, Jr. J. D. Fundamentals of Aerodynamics, $5^{\text {th }}$ ed; TATA McGraw-Hill Education Pvt. Ltd, New Delhi; pp. 274. 
3. Modi, V. J. Mokhtarian, F. Effect of moving surfaces on the aerofoils boundary-layer control, Journal of Aircraft, AIAA, 1988, vol. 27(1), pp. 42-50.

4. Modi, V. J., Munshi, S. R. Bandyopadhyay, G. High-performance aerofoils with moving surface boundary layer control, Journal of Aircraft, AIAA, 1998, vol. 35(4), pp. 544-553.

5. Modi, V. J., Mokhtarian, F., Fernando, M. S. Moving surface boundary-layer control as applied to two-dimensional aerofoils, Journal of Aircraft, AIAA, 1991, vol. 28(2), pp. 104-112.

6. Modi, V.J. Moving surface boundary-layer control: A review, Journal of fluids and structures. 1997, vol. 11(6), pp. 627-663.

7. Modi, V. J., Triplett, B. Moving Surface Boundary-layer Control for Aircraft Operation at High Angles of Attack, The $41^{\text {st }}$ Aerospace Sciences Meeting end Exhibit, Reno, Nevada, 2003.

8. Modi, V.J., Fernando, M.S., Yokomizo T. Moving surface boundary-layer control-Studies with bluff bodies and application, AIAA journal. 1991, vol. 29(9), pp. 1400-1406.

9. Modi, V. J., Yokomizo, T. On the boundary-layer control through momentum injection: Studies with applications, Sadhana, 1994, vol. 19(3), pp. 401.

10. Modi, V.J., Deshpande, V. A Joukowski airfoil with momentum injection, Atmospheric Flight Mechanics Conference, Guidance, Navigation, and Control and Co-located Conferences, Denver, CO, U.S.A. 2010.

11. Moktarian, F., Modi, V.J. Fluid dynamics of airfoils with moving surface boundary-layer control, Journal of aircraft, 1988, vol. 25(2), pp. 163-169.

12. Johnson, W. S., Tennant, J. S., Stamps, R. E. Leading edge rotating cylinder for boundary-layer control on lifting surfaces, AIAA Journal of Hydronautics, 1975, vol. 9, pp. 76-78.

13. Tennant, J. S., Johnson, W. S., Korthapalli, A. Rotating cylinder for circulation control on an airfoil, AIAA Journal of Hydronautics, 1976, vol. 10, pp. 102-105.

14. Tennant, J. S., Johnson, W. S., \& Keaton, D. D. On the calculation of boundary-layers along rotating cylinders, AIAA Journal of Hydronautics, 1977, vol. 11, pp. 61-63.

15. Tennant, J. S., Johnson, W. S., \& Keaton, D. D. Boundary-layer flow from fixed to moving surfaces including gap effects, AIAA Journal of Hydronautics, 1978, vol. 12, pp. 81-84.

16. Mokhtarian, F., Modi, V.J., Yokomizo, T. Rotating air scoop as airfoil boundary-layer control, Journal of Aircraft, 1988, vol. 25(10), pp. 973-975.

17. Hassan, A., Sankar, L.N. Separation control using moving surface effects - a numerical simulation, Journal of aircraft, 1992, vol. 29(1), pp. 131-139.

18. Al-Garni, A.Z., Al-Garni, A.M., Ahmed, S.A., Sahin, A.Z. Flow control for an airfoil with leading-edge rotation: an experimental study, Journal of Aircraft, 2000, vol. 37(4), pp. 617-622.

19. Yahiaoui, T., Belhenniche, M., Imine, B. Effect of moving surface on NACA 63218 aerodynamic performance, EPJ Web of Conferences, 2015, vol. 92, pp. 02114.

20. Seifert, J. A. Review of the Magnus effect in aeronautics, Progress in Aerospace Sciences, 2012, vol. 55, pp. 17-45.

21. Patkunam, K., Sigamani, S., Mahathi, P., Selvakumaran, T. Experimental study of magnus effect over an aircraft wing, International Journal of Research in Engineering and Technology, 2015, vol. 4(10), pp. 406-415.

22. Kenyon, K. E. On the Magnus effect, Natural Science, 2016, vol. 8(52), pp. 49-52.

23. Sailaranta, T. Studies on Unmanned Atmospheric Flight, Doctoral Dissertation, 2016, 40, Aalto University publication Series.

24. Chen Li. Experimental investigation on moving surface boundary layer control, Master Thesis, Graduate School of National University of Defense Technology. Changsha, Hunan, China, 2007.

25. Buerge, B. T. The vortex flap: an experimental investigation into the use of external rotating cylinders for lift augmentation, In Proceedings of inter-national powered lift conference, London, 2009.

26. Zhang, Y.Y., Huang, D. G., Sun, X. J., Wu, G. Q. Exploration in optimal design of an airfoil with a leading edge rotating cylinder, Journal of Thermal Science, 2010, vol. 19(4), pp. 318-325.

27. Sahu, R., Patnaik, B.S.V. CFD simulation of momentum injection control past a streamlined body, International Journal of Numerical Methods for Heat E Fluid Flow, 2011, vol. 21(8), pp. 980-1001.

28. Ahmed, S., Nazari, A., Wahba, E. Numerical analysis of separation control over an airfoil section, International Review of Aerospace Engineering, 2014, vol. 7(2), pp. 61-68.

29. Welsh, D.N., Lester, M., Lopes, M., Gates, R., Hoover, J. The effects of a leading edge rotating cylinder on the performance of a NACA 0015 airfoil at high angles of attack, In AIAA Atmospheric Flight Mechanics Conference, 2014, 0540 . 
30. Huda, M. N., Ahmed, T., Ahmed, S. M. S., Salam, M. A., Afsar, M. R., Faisal, K. M., Ali, M. A. T. Study of NACA 0010 symmetric airfoil with leading edge rotating cylinder in a subsonic wind tunnel, The $11^{\text {th }}$ International Conference on Mechanical Engineering, BUET, Dhaka, 2015.

31. Faisal, K. M., Salam, M. A., Ali, M. A. T., Sarkar, M. S., Safa, W., Sharah, N. Flow control using moving surface at the leading edge of aerofoil, Journal of Mechanical Engineering, 2017, vol. 47(1), pp. 45-50.

32. Alias, M. S., Rafie, A. M., Marzuki, O. F., Hamid, M. A., Chia, C. C. Two dimensional numerical analysis of aerodynamic characteristics for rotating cylinder on concentrated air flow, IOP Conference Series: Materials Science and Engineering, 2017, vol. 270 (1), 012003.

33. Najdat, N. A., Mustafa, F. H. Effect of Gap between Airfoil and Embedded Rotating Cylinder on the Airfoil Aerodynamic Performance, Res Dev Material Sci., 2018, vol. 3(4), pp. 1-10.

34. Vinayaka D. M., Mubeena, J. K. Effect of freely rotating cylinder mounted near the trailing edge of the wing for boundary layer separation delay, International Research Journal of Engineering and Technology (IRJET), 2018, vol. 5(9), pp. 255-261.

35. Aktharuzzaman, M., Sarker, M. S., Safa, W., Sharah, N., Salam, M. A. Development of an experimental setup for analyzing the influence of Magnus effect on the performance of airfoil, AIP Conference Proceedings, 2018, 1919, 020032.

36. Yakhot, V., Orszag, S.A., Thangam, S., Gatski, T.B., Speziale, C.G. Development of turbulence models for shear flows by a double expansion technique, Physics of Fluids A, 1992, vol. 4(7), pp. 1510-1520.

37. ANSYS Fluent, Academic Research Mechanical, Release 18.1, Help System, Coupled Field Analysis Guide, ANSYS, Inc.

38. Henkes, R. A. W. M., van der Flugt, F. F., and Hoogendoorn, C. J. Natural Convection Flow in a Square Cavity Calculated with Low-Reynolds-Number Turbulence Models, Int. J. Heat Mass Transfer, 1991, vol. 34, pp. 1543-1557.

39. ANSYS Fluent Theory Guide, ANSYS, Inc., 275 Technology Drive Canonsburg, PA 15317, November 2013.

40. Khan, N.A., Salam, M. A., Faisal, K. M., Bhadra, D. Computational study of airfoil performance with the incorporation of a moving surface at the leading edge, AIP Conference Proceedings, 2017, 1980, 040016.

41. Ebna Hai, B. S. M. Finite Element Approximation of Ultrasonic Wave Propagation under Fluid-Structure Interaction for Structural Health Monitoring Systems, Doctoral dissertation, Helmut Schmidt University, Hamburg, Germany, 2017.

42. Ebna Hai, B. S. M., and Bause, M. Numerical study and comparison of alternative time discretization schemes for an ultrasonic guided wave propagation problem coupled with fluid-structure interaction, Computers $\mathcal{E}$ Mathematics with Applications, 2019. (doi:10.1016/j.camwa.2019.01.009)

43. Ebna Hai, B. S. M., Bause, M. and Kuberry, P. A. Modeling and Simulation of Ultrasonic Guided Waves Propagation in the Fluid-Structure Domain by a Monolithic Approach, Journal of Fluid and Structures, 2019, vol. 88, pp. 100-121. (doi:10.1016/j.jfluidstructs.2019.04.014)

44. Ebna Hai, B. S. M., Bause, M. and Kuberry, P. A. Modeling Concept and Numerical Simulation of Ultrasonic Waves Propagation in a Moving Fluid-Structure Domain based on a Monolithic Approach, Applied Mathematical Modelling, 2019. (submitted).

45. Ebna Hai, B. S. M., and Bause, M. Finite Element Approximation of Fluid-Structure Interaction (FSI) Problem with Coupled Wave Propagation, PAMM, 2018, vol. 17(1), pp. 511-512. (doi:10.1002/pamm.201710225)

46. Ebna Hai, B. S. M., and Bause, M. Mathematical Modelling and Numerical Simulation of the On-line Structural Health Monitoring System, in F.-K. Chang and F. Kopsaftopoulos (eds.), Structural Health Monitoring 2017: Real-Time Material State Awareness and Data-Driven Safety Assurance, 2017, vol. 1, pp. 580-587. DEStech Publications Inc. (doi:10.12783/shm2017/13913)

47. Ebna Hai, B. S. M., and Bause, M. Numerical Modeling and Approximation of the Coupling Lamb Wave Propagation With Fluid-Structure Interaction Problem, in Proceedings of the ASME International Mechanical Engineering Congress \& Exposition, Pittsburgh, PA, USA, 2018. (doi: doi:10.1115/IMECE2018-87448)

48. Ebna Hai, B. S. M., Bause, M., and Kuberry, P. A. Finite Element Approximation of the eXtended Fluid-Structure Interaction (eXFSI) Problem, in Proceedings of the ASME 2016 Fluids Engineering Division Summer Meeting collocated with the ASME 2016 Heat Transfer Summer Conference and the ASME 2016 14th International Conference on Nanochannels, Microchannels, and Minichannels, Washington, D.C., USA, 2016. (doi:10.1115/FEDSM2016-7506) 
49. Ebna Hai, B. S. M. and Bause, M. Adaptive Multigrid Methods for eXtended Fluid-Structure Interaction (eXFSI) Problem - Part I: Mathematical Modelling, in Proceedings of the ASME International Mechanical Engineering Congress E Exposition, Houston, USA, 2015. (doi:10.1115/IMECE2015-53265)

50. Ebna Hai, B. S. M., and Bause, M. Finite Element Model-based Structural Health Monitoring (SHM) Systems for Composite Material under Fluid-Structure Interaction (FSI) Effect, the $7^{\text {th }}$ European Workshop on Structural Health Monitoring (EWSHM), In: The e-Journal of Nondestructive Testing E Ultrasonics, NDT.net issue, ISSN 1435-4934, Nantes, France, 2014.

51. Ebna Hai, B. S. M., and Bause, M. Mathematical Modelling of Structural Health Monitoring Systems: Coupling Fluid-Structure Interaction with Wave Propagation., in Proceedings of the 7th European Conference on Computational Fluid Dynamics (ECFD), Glasgow, UK, 2018. 